\title{
Preferred Service Investment in the Dual-Channel Supply Chain: Leader-Follower Relationships and Product Characteristics
}

\author{
Wanmei Zhao $\mathbb{D}^{1,2}$ Chunming Ye $\mathbb{D}^{1}{ }^{1}$ and Xiaodong Ding ${ }^{1}$ \\ ${ }^{1}$ Business School, University of Shanghai for Science and Technology, Shanghai 200093, China \\ ${ }^{2}$ School of Business, Shanghai University of International Business and Economics, Shanghai 201620, China \\ Correspondence should be addressed to Chunming Ye; yechm@usst.edu.cn
}

Received 9 December 2019; Revised 27 March 2020; Accepted 20 April 2020; Published 12 May 2020

Academic Editor: Anna M. Gil-Lafuente

Copyright (C) 2020 Wanmei Zhao et al. This is an open access article distributed under the Creative Commons Attribution License, which permits unrestricted use, distribution, and reproduction in any medium, provided the original work is properly cited.

This paper examines the influence that members' preferred service investments have on their decision-making and profits in a dual-channel supply chain. We discuss changes in the supplier's and retailer's decision-making and optimal profits with reference to their different preferred service investment combination modes and their different leader-follower relationships. We also provide classified comparisons of the supplier's and retailer's optimal profits by referring to four types of product characteristics combination modes that are assessed across two channels. By providing classifications and comparisons, we put forward operational insights for the supplier and retailer who have direct implications for their optimal decisions and profits, including selling products with higher homogeneity between two channels, choosing the retailer as the leader of the supply chain, and confirming appropriate preference combination mode under a certain product characteristics. We analyze the influences of the preferred service investment levels as well as preference intensities of the supplier and retailer on their strategies and profits in their respective advantaged states and obtain some enlightenment about the cooperation strategies and relationship-building methods of the supplier and retailer in the actual process of their participation in the dual-channel supply chain operation.

\section{Introduction}

Dual-channel supply chain is a new kind of supply chain mode that is formed by the coexistence of the traditional distribution and the electronic direct channels. It is a new marketing mode that enables supply chain members to sell their products to downstream consumers through two types of channels with the support of IT and Network Marketing [1]. Members in dual-channel supply chain are not normally isolated or independent, but always influence and restrict each other; the decision-making and behavior of one member in one channel will affect another member's decision-making and behavior in another channel, with the consequence that both members' performances and profits will be impacted [2].

In a dual-channel supply chain, members often adopt service investment strategies in their own channels in order to increase their sales volume and improve their profits [3]. Here, "service investment" mainly refers to some service promotion measures from the supplier or retailer to the downstream consumers in order to improve product sales and market share in its own channel in the supply chain [4]. Members' service investment behaviors can be viewed as much of the operations or marketing strategies, such as customer service before and after the sale, product promotions and advertising, and provision of product information [5]. For example, Apple has set up many offline experience stores, which are usually decorated simply and brightly, and the service staff show and introduce the latest products to the customers. The purpose of setting these stores is to "make more customers spend more money on Apple products more easily." Such kind of service investment will influence the product sales and profit of the member in its own channel, which will certainly affect the decision-making and final profits of the other member in the other channel.

During the process of implementing service investment in dual-channel supply chain, each member's mode of service investment will show different characteristic; this is 
because its concept and cognitive level to the dual-channel supply chain are different. For example, a member with an altruistic preference will implement service investment with positive spillover effects in order to increase both channels' sales volume and improve both members' profit. On the contrary, a member with a self-interest preference will implement service investment with negative spillover effects in order to increase his/her own sales volume and profit in his/her own channel, however, will seek to restrain the other member's sales volume and profit in another channel. We can see that service investment with different preferences will have varying impacts on members' decision-making and profits. Study of the influence of different service investment preferences on both the supplier and the retailer in a dualchannel supply chain will reflect their real intentions about the supply chain operation and will make it possible to objectively obtain their final results during their participation in the supply chain operation.

This paper will study the influence of preferred service investment on one or both members in the dual-channel supply chain and will focus in particular on their decisionmaking and profits under different conditions that include different preferred service investment combination modes, leader-follower relationship modes (between the supplier and retailer), and product characteristics combination modes (between two channels). The purpose of our study is to find some reasonable operation strategies and cooperation methods for the supplier and retailer in condition that both of them implement preferred service investment under different objective environments in the dual-channel supply chain.

The remainder of this paper is organized as follows. In Section 2, we give a general introduction about the literature related to our research. In Section 3, we describe the environment and build the models. In Section 4, we investigate the profits of members under their different preferred service investment combination modes based on different leaderfollower relationship modes. In Section 5, we discuss members' optimal decision choices and profits under different product characteristics combination modes and propose advantaged states, respectively, for the supplier and retailer. In Section 6, we examine the influences that members' preferred service investment levels as well as preference intensities have on their strategies and profits in their respective advantage states and propose some conclusions and enlightenments about the cooperation strategies and relationship-building methods of them. We summarize and put forward our future research plan in Section 7.

\section{Literature Review}

Topics related to our research mainly include inter alia, the influence of members' service investment behaviors in a dual-channel supply chain, the influence of members' bounded rational behaviors in a dual-channel supply chain, and the influence of the leader-follower relationship on members in a dual-channel supply chain.
Research on the influence of service investments mainly discusses the influence that service investment has on members' price decisions, profits, and coopetition strategies in a dual-channel supply chain. Tsay and Agrawal [4], Rohm and Swaminathan [6], and Dumrongsiri et al. [7] suggest that service has become an important factor that enables consumers to choose channels and buy a given commodity. Dan et al. [8] and Wang et al. [9] study the optimal retail service and pricing decision in a dual-channel supply chain by applying two-stage optimization method and Stackelberg game. Li et al. [10] discuss and compare three service effort strategies for the retailer in a dual-channel supply chain and propose that members can obtain higher profits in the expost service effort by the retailer's greater showrooming effect. Wu et al. [11] discuss the service level in a dual-channel reverse supply chain (DRSC) and analyze the impact of improving service level and offline transfer price on the profits of DRSC's builder.

Some scholars discuss service spillover effects and free riding phenomena in the dual-channel supply chain. Carlton and Chevalier [12] provide an empirical study that compares the free riding behaviors of the network and entity channels. Bernstein et al. [13] study the manufacturer's increase of overall market demand by introducing sales service into the network direct channel and analyze the positive and negative influence of service spillover effects in a supply chain. Dan et al. [14] compare optimal service levels under different scenarios to investigate the impacts that bidirectional free riding and service competition have on members' decisions.

Some scholars discuss the effects of service on the coordination strategies of supply chain members. Tsay and Agrawal [4] study the dynamic coordination of the supply chain under the influence of price and service factors. Yan and Pei [15] use the bargaining model to realize profitsharing between the dual-channel manufacturer and retailer with the intention of achieving information-sharing equilibrium. Chen and Yang [16] study a service collaboration decision problem in a dual-channel supply chain and find that similar or different services provided by retailers will have different effects on the profits of the supply chain. $\mathrm{Li}$ et al. [17] construct a dual-channel value chain where the retailer provides channel service for its customers and find that the stability region of the decentralized decision model will be narrowed with the increase of service value.

Research into the influence of bounded rational behaviors of members in the (dual-channel) supply chain mainly discusses the influence that members' incompletely rational behavior preferences have on their decision-making and profits. "Bounded Rationality" not only recognizes that human behaviors are consciously rational but also acknowledges this rationality is limited [18]. Scholars maintain that members always show this form of rationality when participating in supply chain operations and observe this has resulted in the study of the Behavioral Supply Chain. They have studied a variety of incompletely rational behavior factors that affect the decision-making behaviors and the final profits of supply chain members, which include altruism, fairness concern, overconfidence, reciprocity, and risk aversion. 
Gan et al. [19], Wang and Webster [20], and Li et al. [21] investigate how a supply chain that involves an upside-riskneutral supplier and a downside-risk-averse retailer can continue to coordinate with each other, and they accordingly design some corresponding contracts that help to accomplish channel coordination. Cui et al. [22] and Ozgun et al. [23] incorporate the concept of fairness into a conventional dyadic channel to investigate how fairness may affect channel coordination and the manufacturer's use of a simple wholesale price to coordinate the channel. Wang and Cheng [24] examine the effect of fairness concern preference on the supply chain partners' strategies upon the basis of a dual-channel supply chain. Ren et al. [25] and $\mathrm{Wu}$ and $\mathrm{Hu}$ [26] explore the characteristics and impact of decision makers' overconfident behaviors in the supply chain by applying classical analysis techniques and discuss the strategies change of the overconfident members in the supply chain and the final impacts on their profits. Disney and Hosoda [27] study a two-echelon supply chain with and discuss how retailers with altruistic attributes can adjust their own profits and affect those of upstream manufacturers and the whole supply chain. Shi and Ma [28] develop learning dynamics and an evolutionary game model to analyze the channels' altruism behavior and find that the evolutionary direction of altruistic behavior is determined by the sensitivity and learning abilities of both members in the dual-channel supply chain.

Research into the influence of the leader-follower relationship in the supply chain mainly discusses the influence of members' game relationships on their decision-making and profits. The leader-follower relationship in the supply chain can also be understood as a kind of game relationship, in which the norms of decision priority and subordination of supply chain members is determined by a status or power gap [29]. The leader-follower relationship can be generally divided into three forms in a two-echelon supply chain, game relationship led by the supplier, by the retailer (also known as the Stackelberg game relationship), and the Nash Equilibrium relationship between the supplier and retailer. Aust and Buscher [30] investigate the different effects of noncooperative and cooperative relationships between the supplier and retailer and specifically reference their benefits and the customer's effectiveness in different Starkelberg Games. Cai et al. [31] evaluate the impact of price discount contracts and pricing schemes on the dual-channel supply chain competition and expound the advantages of contracts by referring to the perspectives of the supplier Stackelberg, retailer Stackelberg, and Nash Game Theory. Giri and Roy [32] consider a two-echelon dual-channel supply chain with a single manufacturer and multiple retailers and discuss the optimal pricing strategies and effort levels of both the direct channel and retail channel using sequential optimization and the Stackelberg game. Choi et al. [33] explore the optimal prices and maximum profits for both the supplier and retailer under their different power structures. Li et al. [34] examine customer returns and pricing strategies in a manufacturer's Stackelberg dual-channel supply chain by using game-theoretic models and discuss the impact of these two strategies on the prices, demands, and profits of the supplier and retailer.
By reviewing the previous research studies, we think to integrate those topics and make a deeper categorical and expansive research on the dual-channel supply chain. The differences between our research and the previous literature can be summarized as follows.

First, according to the preference characteristics of the supplier and retailer, we divide the function expressions of their sales volume and profits into four sets, which represent four preferred service investment combination modes between them. Previous researchers have often built one service investment combination mode in the dual-channel supply chain, such as the research studies of Tsay and Agrawal [4], Xiao and Yang [35], Dan et al. [8], and Zhang and Wang [36]. They often assume that decision-makers' attitudes towards the coopetition of the dual-channel supply chain are fixed (competitive or cooperative), so the characteristics of their service investment behaviors are constant (self-interest or altruistic) and thus the final influences are always definite (negative or positive). In our study, we propose all possible preference combination modes and extract the most suitable ones for the supplier and retailer. We think it just be obtained by this comprehensive classification method.

Second, we skillfully use a variable $(\lambda)$ to represent the preference characteristics and impact intensities of members' service investment in the dual-channel supply chain. This variable combines the service investment level of the members and is used to describe the impact of preferred service investments on the sales volumes and profits of members in the dual-channel supply chain. We think this application has been less used in the previous literature while we believe it can help us to carry out more comprehensive research.

Third, we propose advantage states, respectively, for the supplier and retailer by comparing their different preferred service investment combination modes and enumerating different product characteristics combination modes across two channels, which are based on the different leader-follower relationship modes between the supplier and retailer. We think it is an innovation of us comparing with previous research studies. Furthermore, we find that few researchers study members' altruistic and self-interest preference simultaneously under multiple game modes. For example, Dumrongsiri et al. [7], Tsay and Agrawal [1], and Chen and Yang [16] study the influence of a game relationship on the coopetition of members in the dual-channel supply chain, but they have only considered one type of relationship mode in each of their research studies. Another example is the research studies of Cai et al. [31], Ren et al. [37], and Choi et al. [33] have introduced two or three relationship modes when discussing the influences of price or service in the dual-channel supply chain, but they do not consider the preference characteristics of the members or using a classification method.

\section{Condition Descriptions and Model Assumptions}

Notations used in this paper are listed in Table 1.

Suppose there is a two-echelon dual-channel supply chain in the market that contains one supplier (represented 
TABLE 1: Notations.

\begin{tabular}{lc}
\hline Notation & Meaning \\
\hline$s$ & The supplier \\
$r$ & The retailer \\
$t$ & The traditional distribution channel \\
$e$ & The electronic direct channel \\
$S$ & Leader-follower relationship led by the supplier \\
$R$ & Leader-follower relationship led by the retailer \\
$N$ & Nash equilibrium game relationship \\
$J J$ & A self-interested supplier and a self-interested retailer \\
$T J$ & An altruistic supplier and a self-interested retailer \\
$J T$ & A self-interested supplier and an altruistic retailer \\
$T T$ & An altruistic supplier and an altruistic retailer \\
$A$ & Potential total market products demand \\
$\alpha$ & Market share of product in the distribution channel \\
$\lambda$ & Service-demand transfer coefficient \\
$\theta$ & Price-demand transfer coefficient \\
$\omega_{t}$ & Wholesale prices in the distribution channel \\
$P_{t}$ & Sales price in the distribution channel \\
$P_{e}$ & Sales price in the electronic direct channel \\
$Q_{t}$ & Sales volume in the distribution channel \\
$Q_{e}$ & Sales volume in the electronic direct channel \\
$k_{s}$ & Supplier's altruistic preference intensity \\
$k_{r}$ & Retailer's altruistic preference intensity \\
$V_{t}$ & Retailer's service investment level in the distribution \\
$V_{e}$ & Tupplier's service investment level in the direct channel \\
$\Pi_{s}$ & The supplier's profit \\
$\Pi_{r}$ & The retailer's profit \\
$U_{s}$ & The supplier's utility \\
$U_{r}$ &
\end{tabular}

as "she") and retailer (represented as "he"). "Dual channel" means there are two sales channels in the supply chain, the traditional distribution channel (hereafter called "distribution channel") consists of an upstream supplier and a downstream retailer, and the electronic direct channel (hereafter called "direct channel") consists of the single supplier. In the distribution channel, the supplier sells her product to the retailer at a wholesale price $\omega_{t}$, and the retailer sells the product to his downstream consumers at price $P_{t}\left(P_{t}>\omega_{t}\right)$. In the direct channel, the same supplier sells her product (same category with product in the distribution channel) directly to her downstream consumers at price $P_{e}$. The conceptual structure of the dual-channel supply chain is shown in Figure 1.

Suppose that during participation in the operation of the dual-channel supply chain, both the supplier in the direct channel and the retailer in the distribution channel confirm their sales volume in accordance with product prices and levels of service investment in relation to two channels. This means that the sales volume of products in one channel is affected not only by its own channel price and the level of service investment but also by the influence of the same factors from another channel, including the impact of degrees of difference between two channels.

We also assume that the service investment behaviors of the supplier and the retailer will show their particular preference characteristics, including self-interest or altruism, for the reason that both of them are bounded rational

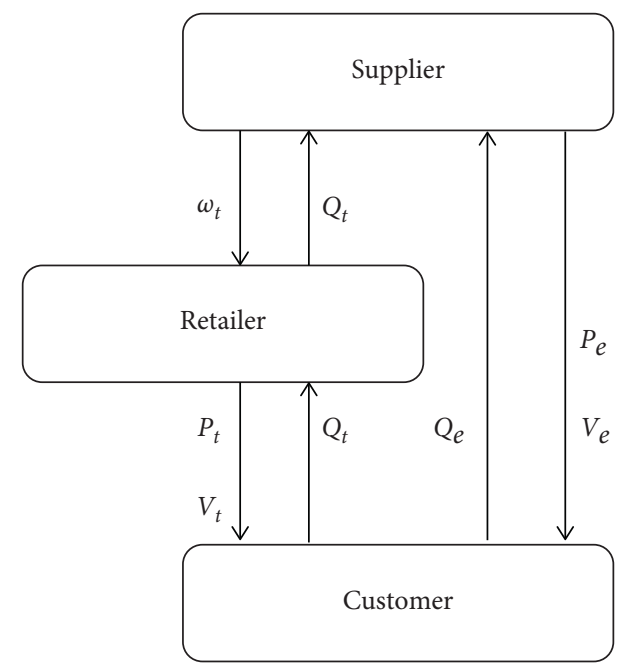

FIgURE 1: Conceptual structure of the dual-channel supply chain.

decision makers. Members with a preference for self-interest will show their self-interest or exclusive characteristics in their service investment behaviors. For example, the retailer in the distribution channel will try to encourage more consumers to buy his product through a traditional offline channel by providing user experiences or product trials in his physical store (Apple, for example), and this may exert certain inhibitory effects on supplier sales in the direct channel. Members with an altruistic preference will also show their reciprocity and altruistic characteristics in their service investment behaviors. For example, the direct channel supplier will take advantage of her richer and more comprehensive information resources in the network in order to encourage more consumers to buy products from offline stores in a shorter period of time and with lower transportation costs; in this condition, the supplier's service investment behavior in the direct channel will create positive spillover effects that will impact on retailer's sales in the distribution channel. When a member has altruistic preference, he/she will not seek to maximize his/her own profit, but will instead maximize the profit of all members. His/her ultimate aim is to maximize optimal utility rather than optimal profit during participation in the supply chain operation. In this condition, we can conclude that any member's preferred service investment behavior and preferred decision will influence all members' decisions and profits. In the case of the dual-channel supply chain, this will also apply to the whole supply chain's profit.

Now consider that sales volume in a dual-channel supply chain is affected by many factors that reflect the characteristics of the dual-channel supply chain, with the exception of prices and service investment levels, such as the price-demand transfer coefficient and the service-demand transfer coefficient. We, respectively, use $Q_{t}$ and $Q_{e}$ to represent the sales volume of products in the distribution channel and direct channel, and then express $Q_{t}$ and $Q_{e}$ in the terms set out in Table 2 .

In Table $2, k_{s}$ and $k_{r}$, respectively, represent the altruistic preference intensity of the supplier and the retailer, $0 \leq k_{s}$, $k_{r}<1, k_{s}=0$ means the supplier is completely self-interested, $0<k_{s}<1$ means she has altruistic preference, and the 
TABLE 2: Sales volume expressions of the supplier and retailer based on their different preferred service investment combination modes.

\begin{tabular}{lll}
\hline Preference characteristics & Supplier is self-interested $\left(k_{s}=0\right)$ & Supplier is altruistic $\left(0<k_{s}<1\right)$ \\
\hline Retailer is self-interested $\left(k_{r}=0\right)$ & $Q_{t}=\alpha A-P_{t}+\theta P_{e}+V_{t}-\lambda V_{e}$ & $Q_{t}=\alpha A-P_{t}+\theta P_{e}+V_{t}+\lambda V_{e}$ \\
& $Q_{e}=(1-\alpha) A-P_{e}+\theta P_{t}+V_{e}-\lambda V_{t}$ & $Q_{e}=(1-\alpha) A-P_{e}+\theta P_{t}+V_{e}-\lambda V_{t}$ \\
Retailer is altruistic $\left(0<k_{r}<1\right)$ & $Q_{t}=\alpha A-P_{t}+\theta P_{e}+V_{t}-\lambda V_{e}$ & $Q_{t}=\alpha A-P_{t}+\theta P_{e}+V_{t}+\lambda V_{e}$ \\
& $Q_{e}=(1-\alpha) A-P_{e}+\theta P_{t}+V_{e}+\lambda V_{t}$ & $Q_{e}=(1-\alpha) A-P_{e}+\theta P_{t}+V_{e}+\lambda V_{t}$ \\
\hline
\end{tabular}

intensity of her altruistic preference will increase as $k_{s}$ increases. The meaning of $k_{r}$ is similar to $k_{s}$.

Suppose that a member's service investment in the dualchannel supply chain always has a positive effect on its own product sales. However, in another channel, the effect may have a different effect on another member's product sales because of the different preferences of its service investment. That means, if a member is a completely self-interested decision-maker, its service investment will negatively affect another member's product selling in another channel. On the contrary, if she is an altruistic decision-maker, her service investment will have a positive effect. On the basis of this analysis, we can build four combination modes that reflect the supplier's and retailer's different preferred service investment, as shown in Table 2.

$V_{t}>0$ and $V_{e}>0$ represent the retailer's (in distribution channel) and the supplier's (in direct channel) service investment levels. $A>0$ represents the product's potential total market demand. $0<\alpha<1$ represents the product's market share in the distribution channel. $0<\theta<1$ means the price-demand transfer coefficient which, due to price differences between two channels, represents the transfer of sales volume and also indicates product heterogeneity between two channels.

Product characteristics mainly include the difficulty and heterogeneity characteristics of product selling across two channels. In this paper, market share of product $(\alpha)$ and the price-demand transfer coefficient $(\theta)$ are two environmental parameters that show the product characteristics in the dualchannel supply chain. $0.5<\alpha<1$ means products are easier to sell in the distribution channel (such as fresh food), while $0<\alpha<0.5$ means products are easier to sell through the direct channel (virtual products such as network game). $0.5<\theta<1$ means there is a high degree of homogeneity between products from two channels, and accordingly an increased sales price in one channel will have a strong positive effect on sales volume in another channel (such as books and electronics); $0<\theta<0.5$ indicates that products have high heterogeneity between two channels, and accordingly the increase of the sales price in one channel will have a weaker effect on sales volume in another channel (such as luxuries and cosmetics).

$0<\lambda<1$ means the service-demand transfer coefficient, which represents the transfer of sales volume due to service differences between two channels. In order to make the discussion easier to follow, we assume that the effect of price on sales volume is stronger than service investment, and it therefore just means $\theta>\lambda$. This assumption is consistent with the characteristics of factors that influence product sales in a real market environment.

For purposes of investigative convenience and to ensure that we do not lose generality, we assume that the costs of both members in relation to the selling of products and the implementation of service investment are both 0 . We also assume that all service investment levels $\left(V_{t}, V_{e}\right)$ and the wholesale price of the supplier $\left(\omega_{t}\right)$ are exogenous variables that are not affected by other factors.

Upon the basis of the descriptions and assumptions above, the supplier's and retailer's profit and utility in a dualchannel supply chain can be expressed as $\Pi_{s}, \Pi_{r}, U_{s}$, and $U_{r}$, which can be described as follows:

$$
\begin{aligned}
& \Pi_{s}=\omega_{t} Q_{t}+P_{e} Q_{e}, \\
& \Pi_{r}=\left(P_{t}-\omega_{t}\right) Q_{t}, \\
& U_{s}=\Pi_{s}+k_{s} \Pi_{r}=\omega_{t} Q_{t}+P_{e} Q_{e}+k_{s}\left(P_{t}-\omega_{t}\right) Q_{t}, \\
& U_{r}=\Pi_{r}+k_{r} \Pi_{s}=\left(P_{t}-\omega_{t}\right) Q_{t}+k_{r}\left(\omega_{t} Q_{t}+P_{e} Q_{e}\right)
\end{aligned}
$$

According to the expressions of $Q_{t}$ and $Q_{e}$ in Table 2, we can obtain the utility expressions of the supplier and the retailer expressed by $P_{t}, P_{e}, \omega_{t}, \alpha, \theta, \lambda, V_{t}$, and $V_{e}$.They are in accordance with the supplier's and retailer's different preferred service investment combination modes, which are shown in Table 3 .

The superscript letter combinations for $U$, " $J J$ " means that both the supplier and retailer are self-interested, " $T J$ " means the supplier is altruistic and the retailer is self-interested, and other letter combinations have similar meanings. In the case of subscript letters for $U$, " $s$ " represents the supplier and " $r$ " represents the retailer.

In Section 4, we will discuss the effect that members' preferred service investments have on their sales strategies and profits by referring to three different types of leader-follower relationship modes that conjoin the supplier and retailer.

\section{Influences of Preferred Service Investments under Different Leader-Follower Relationship Modes}

It has already been noted that the different subordinate status of the supplier and retailer in the dual-channel supply chain enables the leader-follower relationships modes to be divided into three types, Stackelberg game led by the supplier, Stackelberg game led by the retailer, and Nash Equilibrium Game between the supplier and the retailer. By applying this classification and referring to expressions (1) (4) and Tables 2 and 3, we can obtain the supplier's and retailer's optimal sales price and sales volume that apply under different preferred service investment combination modes that are in turn based on each type of their leader-follower relationship mode. 
TABLE 3: Utility expressions of the supplier and the retailer according to their different preferred service investment combination modes.

\begin{tabular}{|c|c|c|}
\hline $\begin{array}{l}\text { Preference } \\
\text { characteristic }\end{array}$ & Supplier is self-interested $\left(k_{s}=0\right)$ & Supplier is altruistic $\left(0<k_{s}<1\right)$ \\
\hline \multirow{2}{*}{$\begin{array}{l}\text { Retailer is } \\
\text { self-interested } \\
\left(k_{r}=0\right)\end{array}$} & $\begin{array}{l}U_{s}^{J J}=\Pi_{s}^{J J} \\
=\omega_{t}\left(\alpha A-P_{t}+\theta P_{e}+V_{t}-\lambda V_{e}\right) \\
+P_{e}\left[(1-\alpha) A-P_{e}+\theta P_{t}+V_{e}-\lambda V_{t}\right]\end{array}$ & $\begin{array}{l}U_{s}^{T J}=\left[k_{s} P_{t}+\left(1-k_{s}\right) \omega_{t}\right]\left(\alpha A-P_{t}+\theta P_{e}+V_{t}+\lambda V_{e}\right) \\
+P_{e}\left[(1-\alpha) A-P_{e}+\theta P_{t}+V_{e}-\lambda V_{t}\right]\end{array}$ \\
\hline & $\begin{array}{l}U_{r}^{J J}=\Pi_{r}^{J J} \\
=\left(P_{t}-\omega_{t}\right)\left(\alpha A-P_{t}+\theta P_{e}+V_{t}-\lambda V_{e}\right)\end{array}$ & $\begin{array}{l}U_{r}^{T J}=\Pi_{r}^{T J} \\
=\left(P_{t}-\omega_{t}\right)\left(\alpha A-P_{t}+\theta P_{e}+V_{t}+\lambda V_{e}\right)\end{array}$ \\
\hline \multirow{2}{*}{$\begin{array}{l}\text { Retailer is } \\
\text { altruistic } \\
\left(0<k_{r}<1\right)\end{array}$} & $\begin{array}{l}U_{s}^{J T}=\Pi_{s}^{J T} \\
=\omega_{t}\left(\alpha A-P_{t}+\theta P_{e}+V_{t}-\lambda V_{e}\right)+ \\
P_{e}\left[(1-\alpha) A-P_{e}+\theta P_{t}+V_{e}+\lambda V_{t}\right]\end{array}$ & $\begin{array}{l}U_{s}^{T T}=\left[k_{s} P_{t}+\left(1-k_{s}\right) \omega_{t}\right]\left(\alpha A-P_{t}+\theta P_{e}+V_{t}+\lambda V_{e}\right) \\
+P_{e}\left[(1-\alpha) A-P_{e}+\theta P_{t}+V_{e}+\lambda V_{t}\right]\end{array}$ \\
\hline & $\begin{array}{l}U_{r}^{J T}=\left[P_{t}-\left(1-k_{r}\right) \omega_{t}\right]\left(\alpha A-P_{t}+\theta P_{e}+V_{t}-\lambda V_{e}\right) \\
+k_{r} P_{e}\left[(1-\alpha) A-P_{e}+\theta P_{t}+V_{e}+V_{t}\right]\end{array}$ & $\begin{array}{l}U_{r}^{T T}=\left[P_{t}-\left(1-k_{r}\right) \omega_{t}\right]\left(\alpha A-P_{t}+\theta P_{e}+V_{t}+\lambda V_{e}\right) \\
+k_{r} P_{e}\left[(1-\alpha) A-P_{e}+\theta P_{t}+V_{e}+\lambda V_{t}\right]\end{array}$ \\
\hline
\end{tabular}

For example, when both the supplier and the retailer implement self-interested service investments and the supplier is the leader in the dual-channel supply chain, the process of Starckelberg Game can be described as follows. Under the premise of a given wholesale price $\omega_{t s}^{J J}$, the supplier first proposes her direct selling price $P_{e s}^{J J}$, and then in accordance with $\omega_{t s}^{J J}$ and $P_{e s}^{J J}$ the retailer decides his distribution price $P_{t s}^{J J}$; both of them aim to maximize their own profits in this situation. Referring to expressions (1) and (2), Tables 2 and 3, adopting the backward induction method and in accordance with the continuity of the first-order derivative and the concavity-convexity of the secondorder derivative, we can obtain the expressions of optimal sales price and sales volume of the supplier and the retailer in "JJ"condition. The deduction process can be described as follows.

It is known from Table 3 that both $U_{r}^{J J}$ and $U_{s}^{J J}$ are second-order and continuous-differential functions about $P_{t}$ and $P_{e}, \partial^{2} U_{s}^{J J} / \partial P_{e}^{2}=\partial^{2} U_{r}^{J J} / \partial P_{t}^{2}=-2<0$ and $\partial^{2} U_{s}^{J J} / \partial P_{e} \partial P_{t}=$ $\partial^{2} U_{r}^{J J} / \partial P_{t} \partial P_{e}=\theta>0$. Let $H$ be the Hessian Matrix about $U_{r}^{J J}$ and $U_{s}^{J J}$, and we can calculate

$$
H=\left(\begin{array}{cc}
\frac{\partial^{2} U_{s}^{J J}}{\partial P_{e}^{2}} & \frac{\partial^{2} U_{s}^{J J}}{\partial P_{e} \partial P_{t}} \\
\frac{\partial^{2} U_{r}^{J J}}{\partial P_{t} \partial P_{e}} & \frac{\partial^{2} U_{r}^{J J}}{\partial P_{t}^{2}}
\end{array}\right)=\left(\begin{array}{cc}
-2 & \theta \\
\theta & -2
\end{array}\right) .
$$

That means $H$ is negative definite and both $U_{s}^{J J}$ and $U_{r}^{J J}$ are concave functions on $P_{t}$ and $P_{e}$, so they can get their maximum values at $P_{e S}^{J *}$ and $P_{t S}^{J *}$.

In accordance with the Stackelberg game led by the supplier, set $\partial U_{r}^{J J} / \partial P_{t}=0$, and we can deduce

$$
P_{t}=\frac{\alpha A+\theta P_{e}+V_{t}-\lambda V_{e}+\omega}{2}
$$

Taking $P_{t}$ into the expression of $U_{s}^{J J}$, we obtain

$$
U_{s}^{J J}=\frac{\omega_{t}\left(\alpha A+V_{t}-\lambda V_{e}-\omega_{t}\right)}{2}+\frac{P_{e}\left[(2-2 \alpha+\alpha \theta) A-\left(2-\theta^{2}\right) P_{e}+\theta P_{t}+(2-\theta \lambda) V_{e}+(\theta-2 \lambda) V_{t}+2 \theta \omega_{t}\right]}{2}
$$

Then, set $\partial U_{s}^{J J} / \partial P_{e}=0$, and we can deduce

$$
P_{e S}^{J J *}=\frac{(2-2 \alpha+\alpha \theta) A+(\theta-2 \lambda) V_{t}+(2-\theta \lambda) V_{e}+2 \theta \omega_{t}}{2\left(2-\theta^{2}\right)} .
$$

Taking $P_{e S}^{J J *}$ into the expression of $P_{t}$ in expression (6), we obtain

$$
P_{t S}^{J J *}=\frac{\left(4 \alpha-2 \alpha \theta-\alpha \theta^{2}+2 \theta\right) A+\left(4-\theta^{2}-2 \theta \lambda\right) V_{t}+\left(2 \theta-4 \lambda+\theta^{2} \lambda\right) V_{e}+4 \omega_{t}}{4\left(2-\theta^{2}\right)}
$$


Taking $P_{e S}^{J J *}$ and $P_{t S}^{J J *}$ into the expression of $Q_{t}$ and $Q_{e}$ in Table 2 (when $k_{s}=0$ and $k_{r}=0$ ), we obtain

$$
\begin{aligned}
& Q_{t S}^{J J *}=\frac{\left(4 \alpha-2 \alpha \theta-\alpha \theta^{2}+2 \theta\right) A+\left(4-\theta^{2}-2 \theta \lambda\right) V_{t}+\left(2 \theta-4 \lambda+\theta^{2} \lambda\right) V_{e}-\left(4-4 \theta^{2}\right) \omega_{t}}{4\left(2-\theta^{2}\right)}, \\
& Q_{e S}^{J J *}=\frac{(2-2 \alpha+\alpha \theta) A+(\theta-2 \lambda) V_{t}+(2-\theta \lambda) V_{e}}{4} .
\end{aligned}
$$

In accordance with expressions (8) (11) and Table 3, we obtain the expressions of the optimal profits of both the supplier and retailer in " $J J$ " condition, which are shown below:

$$
\begin{aligned}
\Pi_{s S}^{J J *}= & {\left[\frac{\left(4 \alpha-2 \alpha \theta-\alpha \theta^{2}+2 \theta\right) A+\left(4-\theta^{2}-2 \theta \lambda\right) V_{t}+\left(2 \theta-4 \lambda+\theta^{2} \lambda\right) V_{e}-\left(4-4 \theta^{2}\right) \omega_{t}}{4\left(2-\theta^{2}\right)}\right]^{2}, } \\
\Pi_{r S}^{J J *}= & \frac{1}{4\left(1-\theta^{2}\right)}\left[(1-\alpha+\alpha \theta) A+(\theta-\lambda) V_{t}+(1-\theta \lambda) V_{e}\right]^{2}+\frac{3}{16}\left(\alpha A+V_{t}-\lambda V_{e}\right)^{2} \\
& -\left[\frac{\left(4 \alpha-2 \alpha \theta-\alpha \theta^{2}+2 \theta\right) A+\left(4-\theta^{2}-2 \theta \lambda\right) V_{t}+\left(2 \theta-4 \lambda+\theta^{2} \lambda\right) V_{e}-\left(4-4 \theta^{2}\right) \omega_{t}}{4\left(2-\theta^{2}\right)}\right]^{2} .
\end{aligned}
$$

Applying the same methods, we can obtain the supplier's and retailer's optimal decision-making and profits in each type of their preferred service investment combination modes that are in turn based on each type of their leaderfollower relationship mode. Expressions of the optimal price and sales volume are listed in Tables 4-6, and the expressions of the corresponding profits are omitted for their complex forms.

\section{Members' Optimal Decision Choices and Profits under Different Product Characteristics}

In this section, we will discuss the supplier's and retailer's optimal decision choices and profits from the perspective of product characteristics. For better investigations and improve comparisons, we will first assign values to some variables that do not relate to the product characteristics; then, under each fixed product characteristics, we will explore the influence of different preferred service investment combination modes on the decision-making and profits of the supplier and retailer based on their different leader-follower relationship modes.

The preceding analyses helps us to grasp that both the market share of product $(\alpha)$ and the price-demand transfer coefficient $(\theta)$ are environmental parameters which represent the product's characteristics (see in Section 3). In drawing on the expressions in Tables 4 6 and combining four combination modes of the value range of $\alpha$ and $\theta$, we can obtain the optimal decisions about the sales prices and volumes along with the final optimal profits of the supplier and retailer under their different leader-follower relationship modes. Set $A=100$, $\omega_{t}=20, \lambda=0.1$, and $V_{t}=V_{e}=80$, and set $k_{s}=k_{r}=0.5$ in condition when either the supplier or the retailer implements altruistic preferred service investment (which can also be understood as either of them evidence an altruistic preference); we can compare members' profits under different conditions, which are shown in Section 5.1.

\subsection{Profits Comparisons of the Supplier and the Retailer Based on Different Product Characteristics}

5.1.1. $0<\alpha<0.5$ and $0<\theta<0.5$. When products are easier to sell through the direct channel and have highly heterogeneity across two channels, we can obtain supplier and retailer profits in different preferred service investment combination modes based on different leader-follower relationship modes, as shown in Figures 2 and 3.

Figures 2 and 3 show that there are four surfaces in each $3 \mathrm{D}$ graph, which represent the supplier's (Figure 2) or retailer's (Figure 3) profits in four types of preferred service investment combination modes under a fixed leader-follower relationship mode. For example, in moving from the bottom to top of Figure 2(a), the observer sees that the surfaces, respectively, show the profits of the supplier on the conditions that both the supplier and the retailer are selfinterested (the red surface), the supplier is altruistic and the retailer is self-interested (the yellow surface), the supplier is self-interested and the retailer is altruistic (the blue surface), and both the supplier and retailer are altruistic (the green surface); this applies under the leader-follower relationship of Stackelberg game led by the supplier. The meanings of other surfaces resemble Figure 2(a). 
TABLE 4: The optimal sales price and sales volume of the supplier and the retailer: different preferred service investments combination modes in the condition of a supplier-led Starckelberg game.

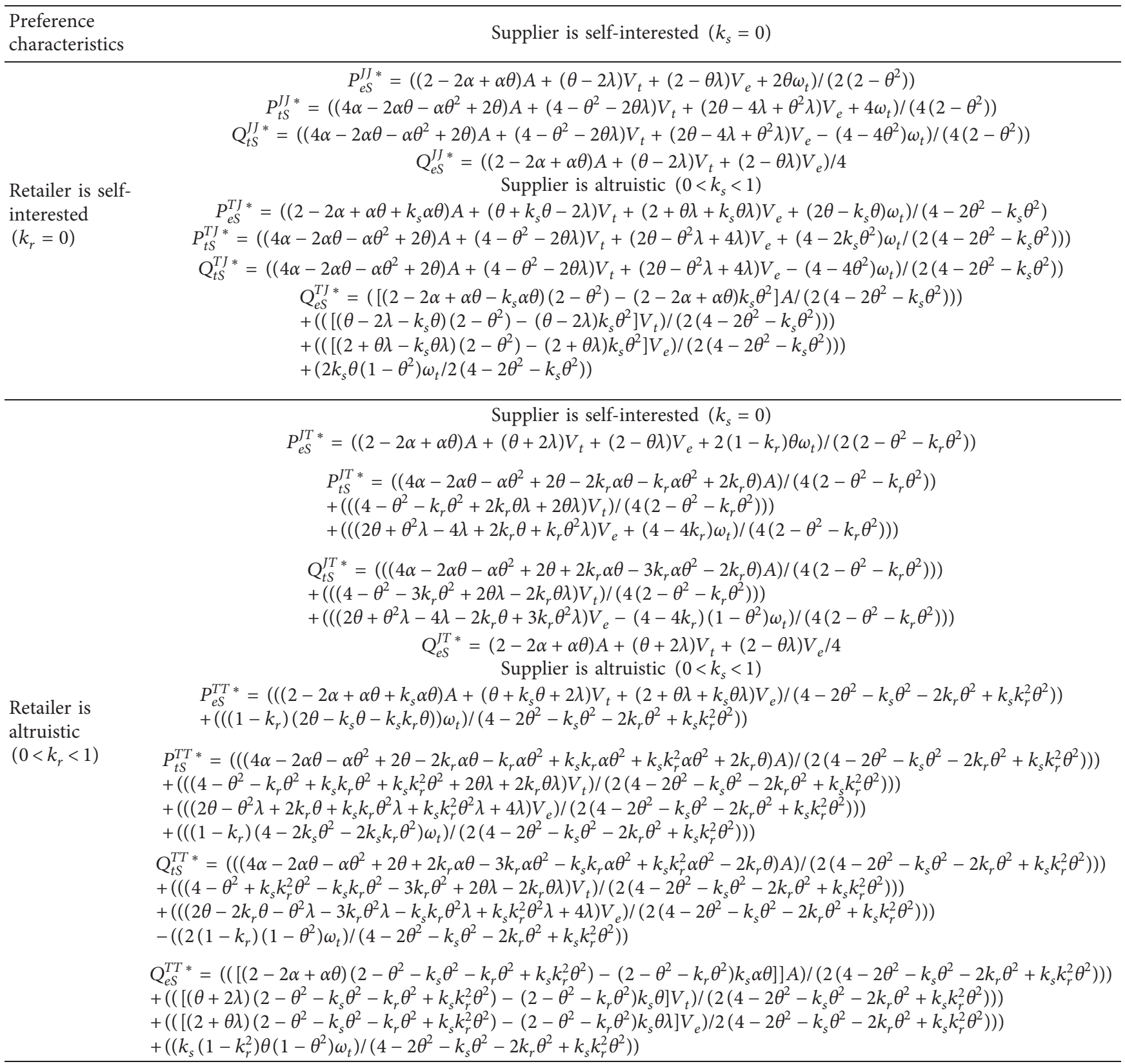

Figure 2 clearly depicts differences in the supplier's profits. Irrespective of the kind of leader-follower relationship modes that conjoin the supplier and retailer, the profit is always lowest for the supplier when both the supplier and retailer are self-interested. Profit is higher when only the retailer is altruistic. When both are altruistic, the supplier can obtain the highest profit.

5.1.2. $0<\alpha<0.5$ and $0.5<\theta<1$. When products are easier to sell through the direct channel and have high homogeneity between two channels, we can obtain supplier and retailer profits in different preferred service investment combination modes based on different leader-follower relationship modes, which are shown in Figures 4 and 5.

These figures make it clear that when products have high homogeneity between two channels, differences in supplier and retailer profits become more obvious in each kind of preferred service investment combination mode, as opposed to the situation that applies when products have high heterogeneity between two channels (see Figures 2 and 3) based on each kind of leader-follower relationship mode. This is because when the pricedemand transfer coefficient $(\theta)$ increases, an increase of price in one channel will have a stronger positive effect on the price in another channel. 
TABLE 5: The optimal sales price and sales volume of the supplier and the retailer: different preferred service investments combination modes in the condition of a retailer-led Starckelberg game.

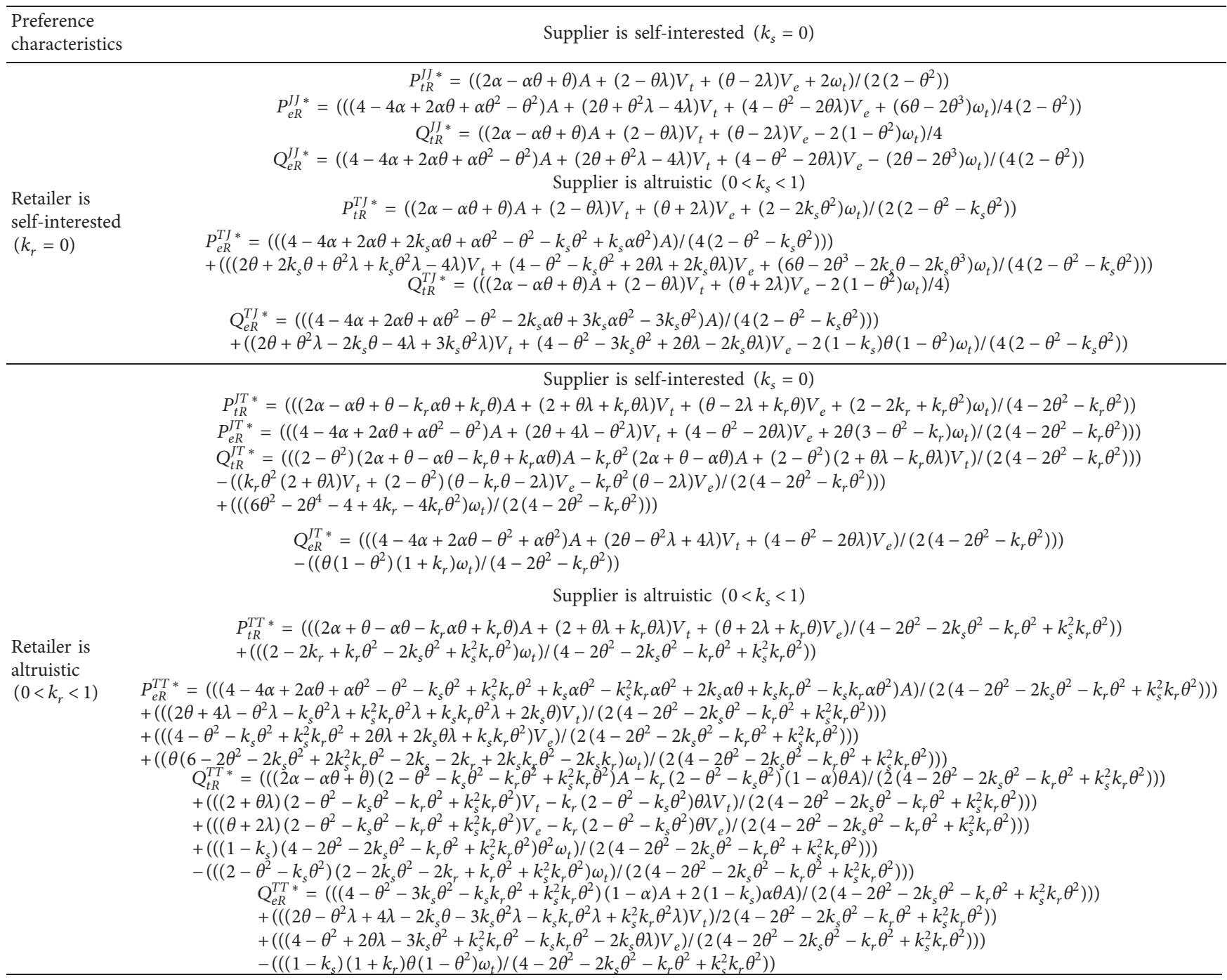

Figures 2-5 demonstrate that the supplier's profit increases as the market share of the product in the direct channel increases (when $\alpha$ falls from 0.5 to 0 ) and at the same time as the retailer's share decreases. This means it is more favorable to the supplier when products can be easily sold through the direct channel, and this is mainly attributable to the fact that it is only the supplier who has ownership of the direct channel. However, when the products are suitable for selling through the distribution channel, the retailer's profit will increase because the ownership of the only channel enables him to sell products.

We observe that both the supplier's and retailer's profit will increase as the price-demand transfer coefficient $(\theta)$ increase, and this reflects the heterogeneity of products between two channels, which can also promote increase of members' profits in each channel.

We also observe that when products are easier to sell through the direct channel $(0<\alpha<0.5)$, the degree of influence on the supplier affected by relevant variables is stronger than that on the retailer. This can be attributed to the supplier's individual ownership of the direct channel. The graphs in Figures 3 and 5 show the retailer's profits under different conditions. In contrast to the supplier, the retailer can obtain a higher profit when it is only the supplier that is altruistic towards him; accordingly, he retains the characteristic of self-interest, especially when he is the leader in the dual-channel supply chain.

5.1.3. $0.5<\alpha<1$ and $0<\theta<0.5$. When products are easier to sell in the distribution channel and have high heterogeneity between two channels, it is possible to obtain the supplier's and retailer's profits in different preferred service investment combination modes based on different leader-follower relationship modes, which are shown in Figures 6 and 7.

5.1.4. $0.5<\alpha<1$ and $0.5<\theta<1$. When products are easier to sell in the distribution channel and have high homogeneity between two channels, we can obtain the supplier's and retailer's profits in different preferred service investment combination modes based on different leader-follower relationship modes, which are shown in Figures 8 and 9.

Figures 6 9 provide similar findings to Figures $2 \sim 5$, such as the comparison of supplier's or retailer's profit in different 
TABLE 6: The optimal sales price and sales volume of the supplier and retailer: different preferred service investments combination modes in the condition of the Nash equilibrium game between two members.

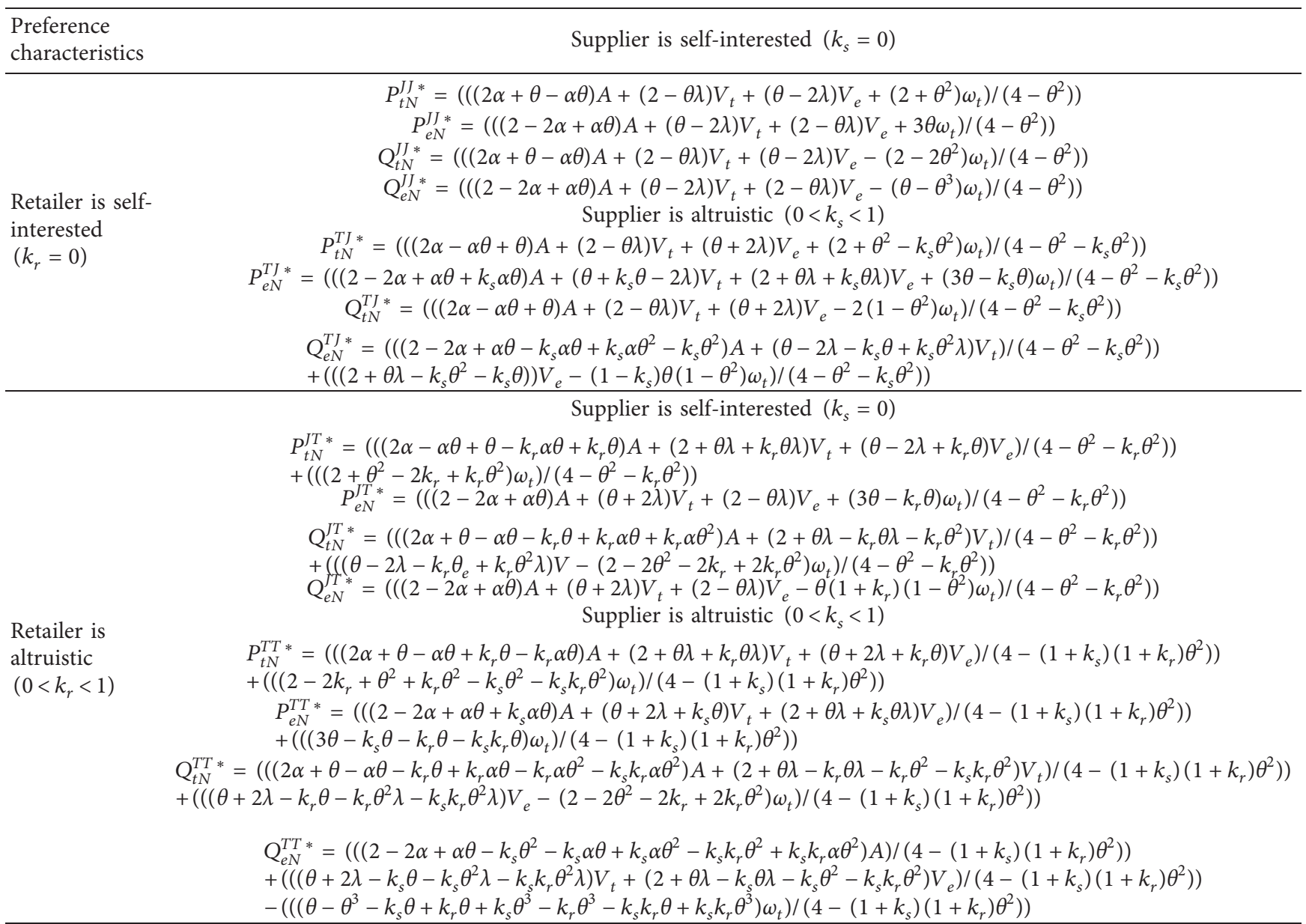

preferred service investment combination modes that are based on different leader-follower relationship modes, the change trend of the profit gap with the price-demand transfer coefficient $(\theta)$ and the influence features on the supplier's and retailer's profit in relation to the market share of product $(\alpha \& 1-\alpha)$. More detailed analyses are omitted here.

5.2. Findings and Enlightenment. The following propositions can be extracted from preceding comparisons and analyses.

Proposition 1. Supplier's profit will increase in accordance with the improvements of product's market share in the direct channel $(1-\alpha)$; retailer's profit will increase in accordance with the improvements of the product's market share in the distribution channel $(\alpha)$.

Proof. We can prove it by choosing a preferred service investment combination mode in a leader-follower relationship mode, and similar methods can be used in other modes.

For example, when the supplier is altruistic and the retailer is self-interested and they are in a supplier-led Stackelberg game (see the yellow surface in each of graph (a) in Figures 2 9), we can obtain the expressions of sales price and volume as well as the profit of both the supplier and retailer by referring to Table 4 . From these expressions, we can deduce

$$
\begin{aligned}
\frac{\partial \Pi_{r S}^{T J *}}{\partial \alpha} & =\frac{4-2 \theta-\theta^{2}}{4-2 \theta-k_{s} \theta^{2}} A\left(Q_{t S}^{T J *}+P_{t S}^{T J *}-\omega_{t}\right)>0, \\
\frac{\partial \Pi_{s S}^{T J *}}{\partial \alpha} & =-\frac{\left(4-2 \theta-k_{s} \theta^{2}\right) Q_{e S}^{T J *}+\left(4-2 \theta-2 \theta^{2}+2 k_{s} \theta-2 k_{s} \theta^{2}+\theta^{3}\right) P_{e S}^{T J *}}{2\left(4-2 \theta-k_{s} \theta^{2}\right)} A-\frac{\left(4-2 \theta-\theta^{2}\right) \omega_{t}}{2\left(4-2 \theta-k_{s} \theta^{2}\right)} A<0 .
\end{aligned}
$$


We can obtain the similar results in any preferred service investment combination mode based on any leader-follower relationship mode, so Proposition 1 can be proved.

Proposition 1 suggests that if the supplier chooses to sell products that are easier to sell through the direct channel, she can obtain more profits because of her ownership of the channel. In common with the retailer, he can obtain more profits when the products are easier to sell through the distribution channel because he can only sell products through it.
Proposition 2. The supplier's and retailer's profits will increase in accordance with the increases in price-demand transfer coefficient $(\theta)$.

Proof. Similarly, we choose the condition as an example that both the supplier and the retailer are self-interested and they are in a retailer-led Stackelberg game (see the red surface in each of graph (b) in Figures 2 9). By referring to the expressions in Table 5, we can deduce

$$
\begin{aligned}
& \frac{\partial P_{t R}^{J J *}}{\partial \theta}=\frac{\left(2-2 \alpha+2 \alpha \theta-\alpha \theta^{2}+\theta^{2}\right) A+\left(4 \theta-\theta^{2} \lambda-2 \lambda\right) V_{t}+\left(2+\theta^{2}-4 \theta \lambda\right) V_{e}+4 \theta \omega_{t}}{2\left(2-\theta^{2}\right)^{2}}>0, \\
& \frac{\partial Q_{t R}^{J J *}}{\partial \theta}=\frac{(1-\alpha) A-\lambda V_{t}+V_{e}+4 \theta \omega_{t}}{4}>0, \\
& \frac{\partial P_{e R}^{J J *}}{\partial \theta}=\frac{\left(4 \alpha-4 \alpha \theta+4 \theta+2 \alpha \theta^{2}\right) A+\left(4+2 \theta^{2}-4 \theta \lambda\right) V_{t}+\left(4 \theta-2 \theta^{2} \lambda-4 \lambda\right) V_{e}}{4\left(2-\theta^{2}\right)^{2}}+\frac{\left(12-6 \theta^{2}+2 \theta^{4}\right) \omega_{t}}{4\left(2-\theta^{2}\right)^{2}}>0, \\
& \frac{\partial Q_{e R}^{J J *}}{\partial \theta}=\frac{\left(4 \alpha-4 \alpha \theta+4 \theta-2 \alpha \theta^{2}\right) A+\left(4+2 \theta^{2}-4 \theta \lambda\right) V_{t}+\left(4 \theta-2 \theta^{2} \lambda-4 \lambda\right) V_{e}}{4\left(2-\theta^{2}\right)^{2}}+\frac{\left(4-10 \theta^{2}+2 \theta^{4}\right) \omega_{t}}{4\left(2-\theta^{2}\right)^{2}}>0, \\
& \frac{\partial \Pi_{s R}^{J J *}}{\partial \alpha}=\frac{\partial P_{e R}^{J J *}}{\partial \theta} Q_{e R}^{J J *}+P_{e R}^{J J *} \frac{\partial Q_{e R}^{J J *}}{\partial \theta}+\omega_{t} \frac{\partial Q_{t R}^{J J *}}{\partial \theta}>0, \\
& \frac{\partial \Pi_{r R}^{J J *}}{\partial \alpha}=\frac{\partial P_{t R}^{J J *}}{\partial \theta} Q_{t R}^{J J *}+\left(P_{t R}^{J J *}-\omega_{t}\right) \frac{\partial Q_{t R}^{J J *}}{\partial \theta}>0 .
\end{aligned}
$$

We can obtain the similar results in any preferred service investment combination mode based on any leader-follower relationship mode, so Proposition 2 can be proved.

Proposition 2 suggests that selling products that have higher homogeneity between two channels will increase the sales volume in both channels and thereby help the members to obtain more profits.

Proposition 3. The supplier can obtain more profits when both the supplier and the retailer implement altruistic preferred service investments in any leader-follower relationship mode and any product characteristics combination mode.

Proof. By referring to the expressions in Tables $4 \sim 6$ and the four surfaces in each $3 \mathrm{D}$ graph in Figures 2, 4, 6, and 8, we can deduce

$$
\Pi_{s i}^{T T *}>\Pi_{s i}^{J T *}>\Pi_{s i}^{T J *}>\Pi_{s i}^{J J *}, \quad i=S, R, N .
$$

So, Proposition 3 can be proved.

Proposition 3 suggests that if the supplier shares altruistic preferences with the retailer at the same time, it will help her gain more profits in comparison with other preferred service investment combination modes in the dual channels.
Proposition 4. The retailer can obtain more profit when the supplier implements altruistic preferred service investment on him and he implements self-interested service investment on the supplier.

Proof. By referring to the expressions in Tables 4 6 and the four surfaces in each 3D graph in Figures 3, 5, 7, and 9, we can deduce

$$
\Pi_{r i}^{T J *} \geq \Pi_{r i}^{f g *}, \quad f, g=J, T ; f g \neq T J ; i=S, R, N .
$$

So, Proposition 4 can be proved.

Proposition 4 suggests that it is the best preference combination mode for the retailer to obtain more profit when only the supplier is altruistic.

Proposition 5. In a condition where there is a certain combination mode of preferred service investment between the supplier and retailer, the leader-follower relationship mode that enables the retailer to act as the leader can create more profit for both the supplier and the retailer than any other leader-follower relationship modes in any product characteristics.

Proof. By referring to the expressions in Tables $4 \sim 6$ and the four surfaces in each 3D graph in Figures 1 9, we can deduce 


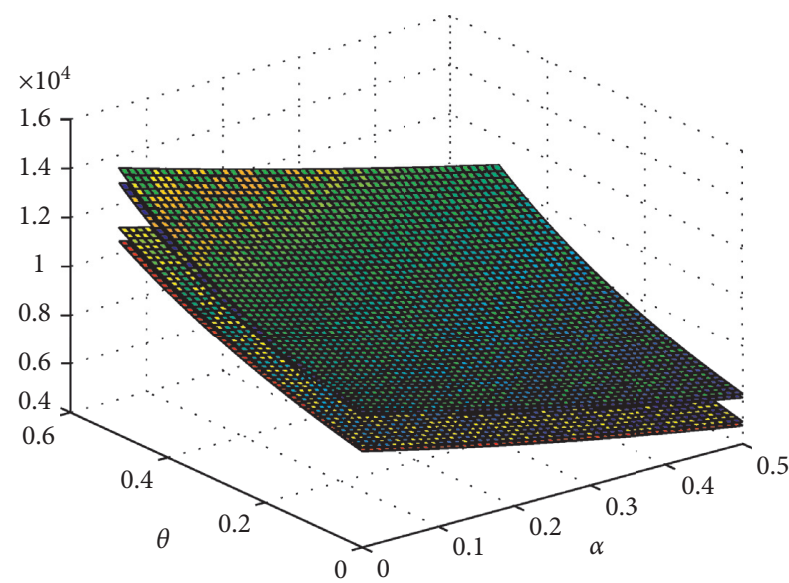

(a)

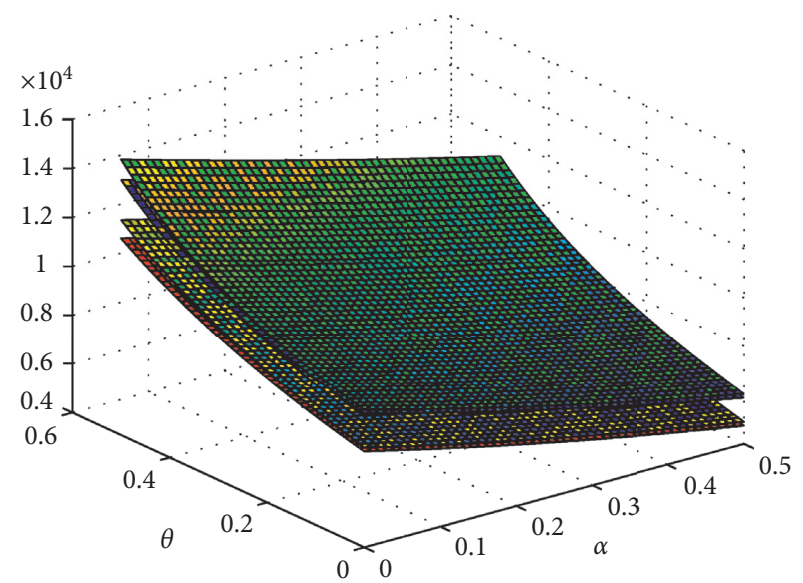

(b)

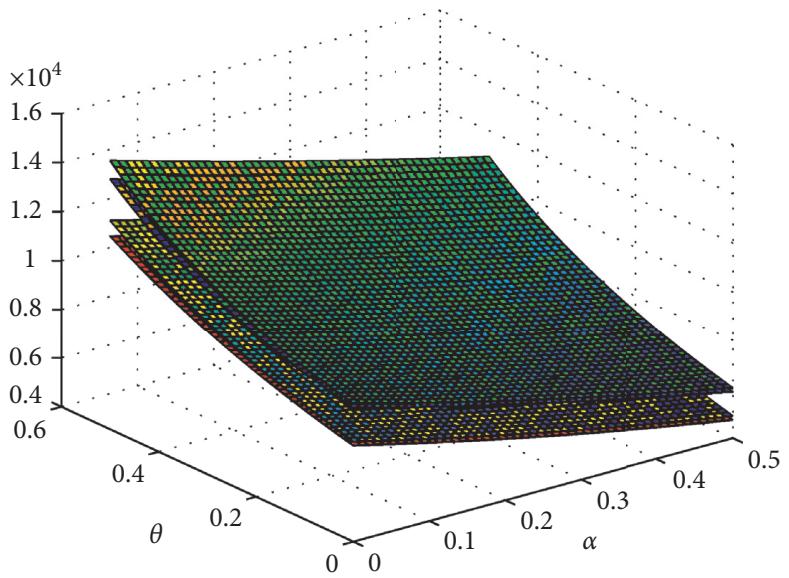

(c)

Figure 2: Comparisons of the supplier's profit in different preferred service investment combination modes based on different leaderfollower relationship modes when products are easier to sell through the direct channel and have high heterogeneity between two channels $(0<\alpha<0.5,0<\theta<0.5)$. (a) Stackelberg game led by the supplier; (b) Stackelberg game led by the retailer; (c) Nash Equilibrium game between the supplier and the retailer.

$$
\Pi_{h R}^{f g *} \geq \Pi_{h i}^{f g *}, \quad f, g=J, T ; h=s, r ; i=S, N .
$$

So, Proposition 5 can be proved.

Proposition 5 suggests that the Stackelberg game led by the retailer is the best choice for both the supplier and retailer in a dual-channel supply chain. This may be because when the retailer is the leader in the dual-channel supply chain, he can get greater decision priority in the distribution channel and the supplier can have more bargaining power in the direct channel, this is especially true when the products have high homogeneity between two channels.

By undertaking comparative analyses of the supplier's and retailer's profits under different conditions, it is possible for us to obtain further enlightenment about strategic cooperation between the supplier and retailer in the dualchannel supply chain.

First, if the dual-channel operation is to be maintained and stabilized, both the supplier and retailer should choose to sell products with higher homogeneity, and this is because it promotes the sales volume for both channels, thus increases the supplier's and retailer's profits. If they instead choose to sell products with lower homogeneity, the effect of price changing on sales volume in the two channels will gradually weaken, and this will cause them both to lose their bargaining powers, which will ultimately lead to the detriment of the dual-channel supply chain's stability.

Second, there is often a power gap between the supplier and retailer that arises from their different strength and status in the dual-channel supply chain. It is generally the case that the stronger one will act as the leader and will take priority in deciding the sales price or the service investment level. These analyses make it clear that, in the case of the supplier and retailer, the dual-channel supply chain led by the retailer may, when compared with other leader-follower relationship modes, be the best means through which they can obtain more profits; this applies irrespective of the kind of preferred service investment combination modes and the kind of product characteristics, especially when the product has high homogeneity between two channels.

Third, the supplier and the retailer often choose to implement different preferred service investments because they have different perceptions of competition or 


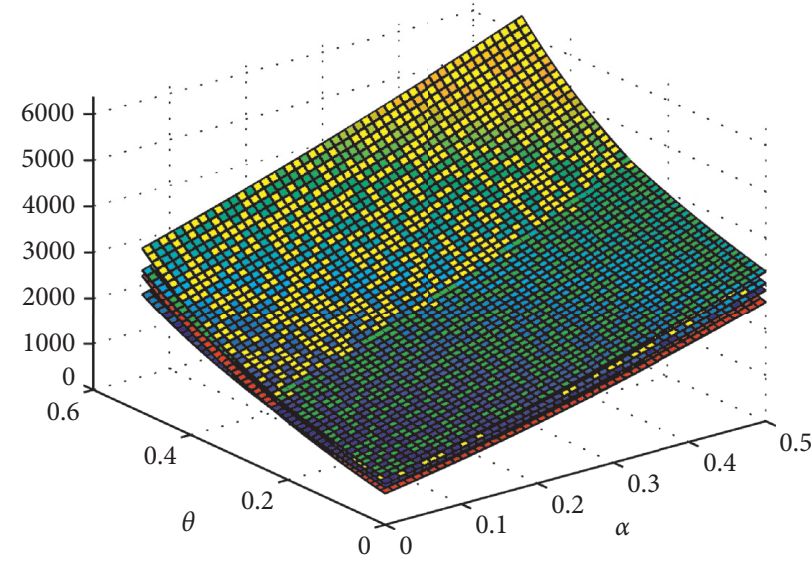

(a)

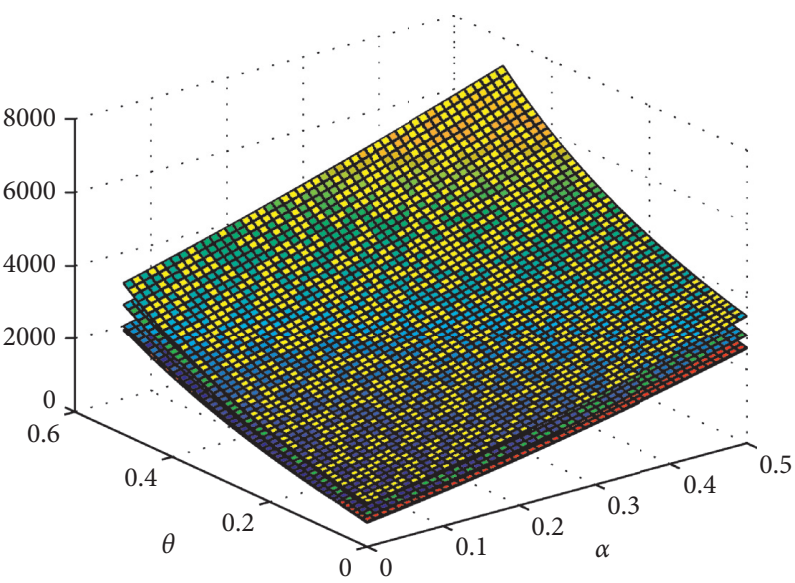

(b)

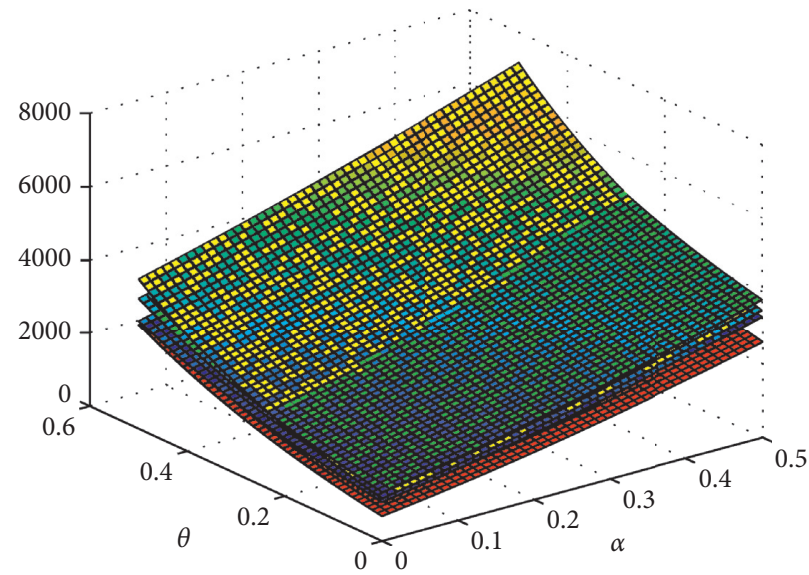

(c)

FIGURE 3: Comparisons of the retailer's profit in different preferred service investment combination modes based on different leaderfollower relationship modes when products are easier to sell through the direct channel and have high heterogeneity between two channels $(0<\alpha<0.5,0<\theta<0.5)$. (a) Stackelberg game led by the supplier; (b) Stackelberg game led by the retailer; (c) Nash Equilibrium game between the supplier and the retailer.

cooperation in the dual-channel supply chain. By referring to analyses, we can see that the supplier, who is in the upstream of the supply chain, is more willing to cooperate with the retailer when they are both altruistic. The retailer, who is in the downstream of the supply chain, is more willing to cooperate with an altruistic supplier and act as a self-interested partner. We therefore think that, in a dualchannel supply chain, it is a favorable situation for the supplier when the retailer acts as the leader and both members implement altruistic preference service investment. When the retailer acts as the leader and only the supplier implements altruistic preference service investment, we regard it as a favorable situation for the retailer.

\section{Members' Strategies and Profits in Their Respective Advantaged States}

Both Propositions 1 5 and enlightenment in Section 5.2 enables us to obtain the advantaged states for the supplier and retailer. We will then investigate how the preferred service investment level and preference intensities of the supplier and retailer influence each other's optimal strategies and final profits in their respective advantage states in the dual-channel supply chain. Our discussion is based on the premise that products are strongly homogeneous between two channels, as we have already discussed.

6.1. Members' Strategies and Profits in the Supplier's Advantaged State. In order to highlight the main purpose and establish a reasonable foundation for our discussion, we first assign values to the variables that do not include the preferred service investment levels and preference intensities. Set $A=100, \omega_{t}=20$, and $\lambda=0.1$ and $\alpha=0.3$ and $\theta=0.7$ (to match the situation where products are easier to sell through the direct channel and have high homogeneity between two channels). Set $k_{s}$ increasing from $0 \sim 1$ and $V_{e}$ increasing from 40 100 when discussing the effect of the supplier's preferred service investment level and preference intensity. Set $k_{r}=$ 0.5 and $V_{t}=40,70,100$ when discussing the effect of the preferred service investment level of the retailer. Respectively, set $V_{t}=70$ and $k_{r}=0.1,0.5,0.9$ when discussing the 


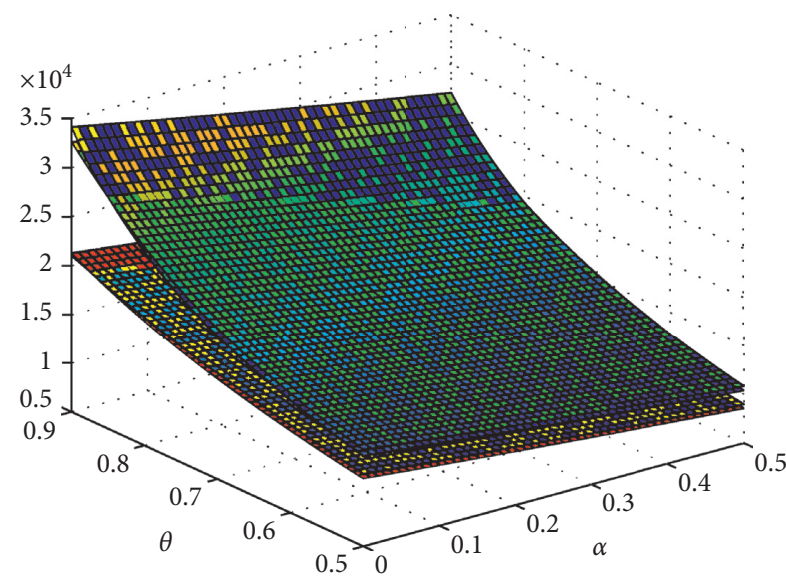

(a)

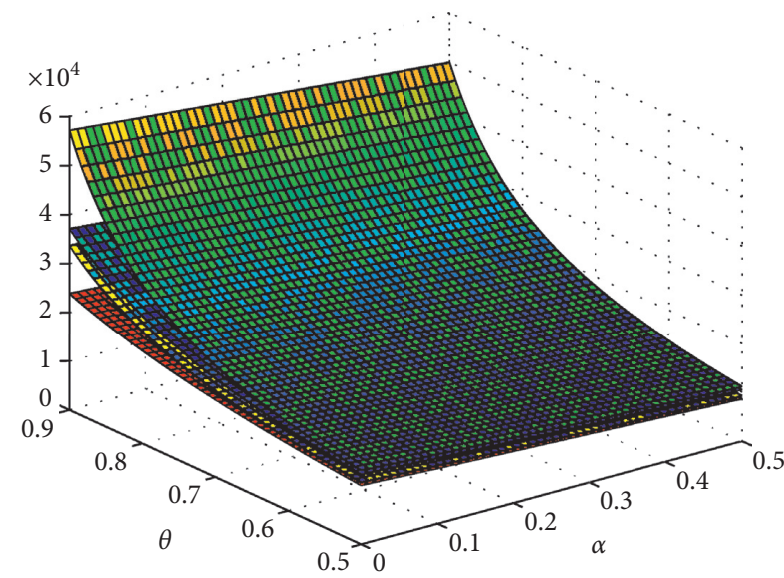

(b)

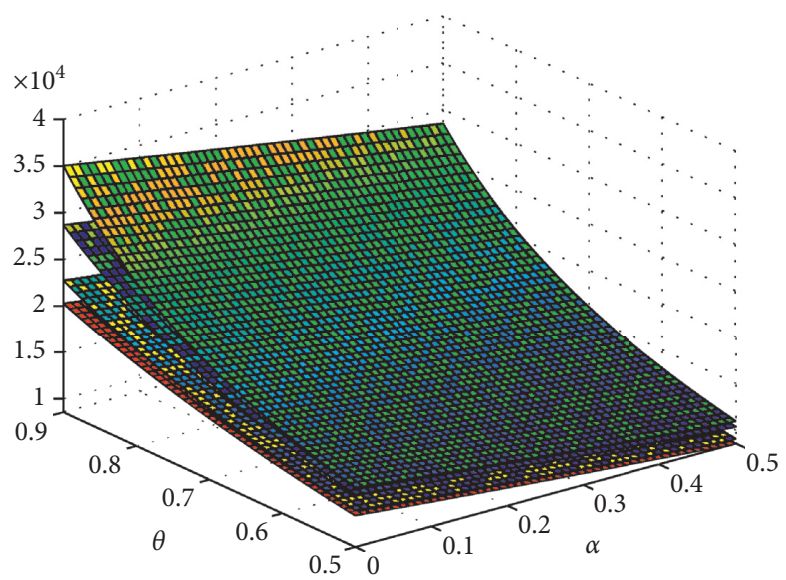

(c)

Figure 4: Comparisons of the supplier's profit in different preferred service investment combination modes based on different leaderfollower relationship modes when products are easier to sell through the direct channel and have high homogeneity between two channels $(0<\alpha<0.5,0.5<\theta<1)$. (a) Stackelberg game led by the supplier; (b) Stackelberg game led by the retailer; (c) Nash equilibrium game between the supplier and the retailer.

effect of preference intensity of the retailer. We can obtain the profit changes of the supplier, which are shown in Figure 10.

There are three surfaces in each 3D graph that represent how supplier's profits are affected by different preferred service investment levels and preference intensities of the supplier and the retailer under the supplier's advantaged state. In moving from the bottom to top of Figure 10(a), the observer sees that the surfaces, respectively, show the profits of the supplier, on the conditions that the altruistic intensity of the retailer is fixed $\left(k_{r}=0.5\right)$ and the service investment levels of him are, respectively, 40, 70 and 100 (be painted red, yellow and blue, respectively), with the continuous distribution of the service investment levels $\left(V_{e}\right.$ increases from 40 100) and preference intensities ( $k_{s}$ increases from $0 \sim 1$ ) of the supplier. Similarly, a reading from the bottom to top of Figure 10(b) shows that the surfaces depict the supplier's different profits on the condition that the retailer's service investment level is fixed $\left(V_{t}=70\right)$ and the altruistic intensities of him are, respectively, 0.1, 0.5 and 0.9 (be painted red, yellow, and blue, respectively), with the continuous distribution of the service investment levels $\left(V_{e}\right.$ increases from 40 100) and preference intensities ( $k_{s}$ increases from $0 \sim 1)$ of the supplier.

We can see that the supplier's profit will increase when either the supplier or the retailer raise their service investment levels. Increases in the retailer's altruistic preference intensity can also increase the supplier's profit. The influence of the supplier's altruistic preference intensity on her own profit shows a trend of initially increasing and then decreasing, and this means when the supplier keeps her altruistic preference at a moderate intensity, she can obtain an optimal profit.

We will then discuss the retailer's profit in the supplier's advantaged state. We can obtain changes in the retailer's profits that have been affected by the preferred service investment levels and the preference intensities of both the supplier and the retailer, which are shown in Figure 11.

Similar to what are shown in Figures 10 and 11(a) makes it clear that the retailer's profit will increase in the supplier's advantaged state when either the supplier or the retailer raise their altruistic preferred service investment levels. Figure 11(b) shows the retailer's profits will increase when 


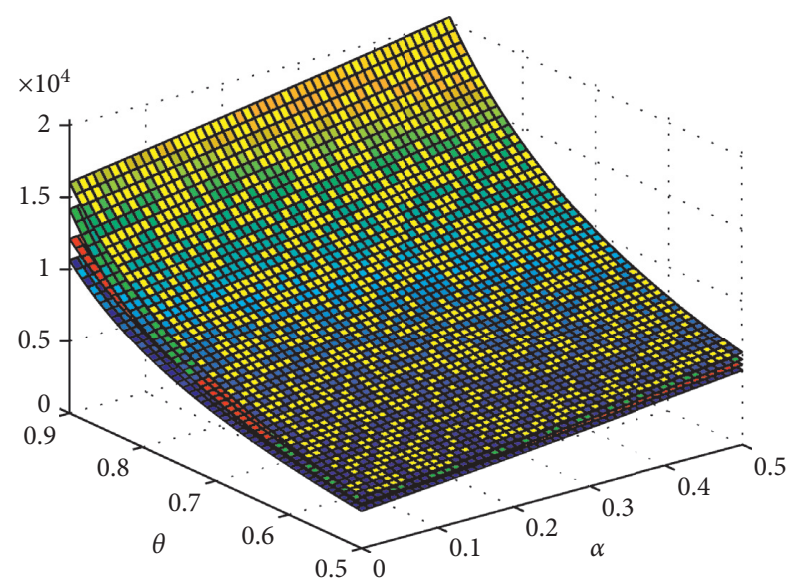

(a)

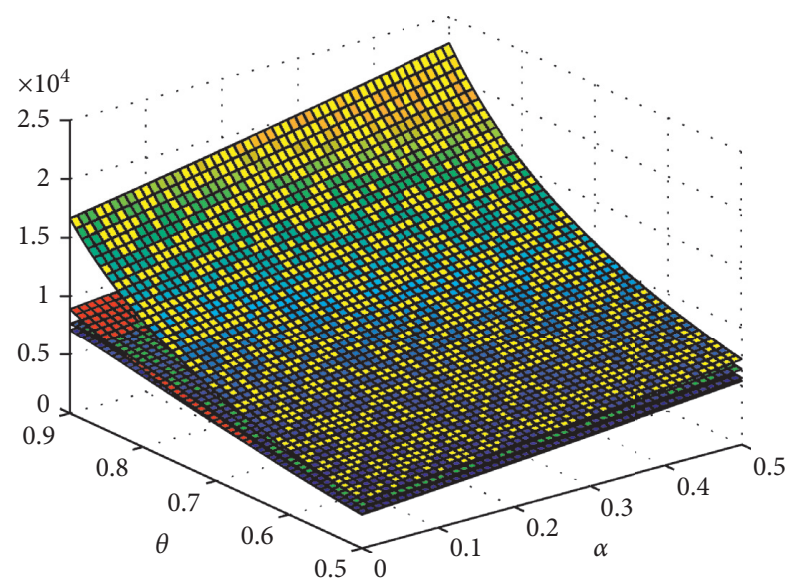

(b)

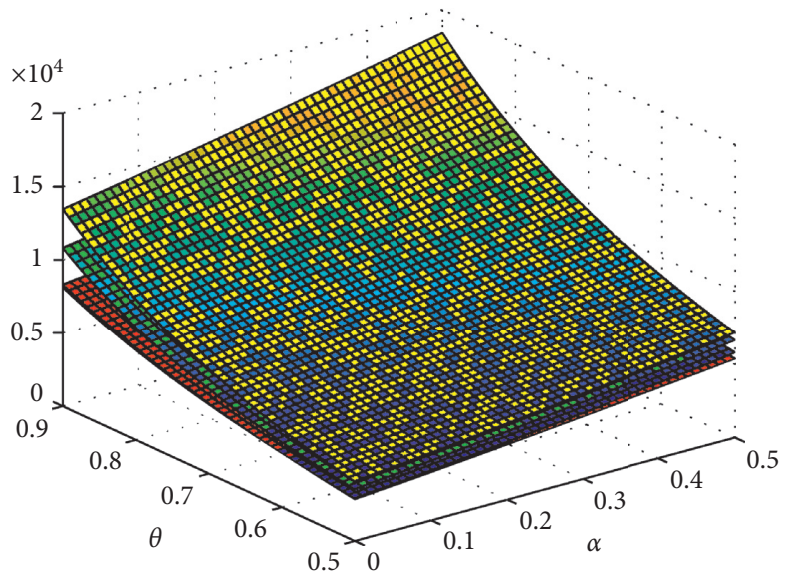

(c)

FIGURE 5: Comparisons of the retailer's profit in different preferred service investment combination modes based on different leaderfollower relationship modes when products are easier to sell through the direct channel and have high homogeneity between two channels $(0<\alpha<0.5,0.5<\theta<1)$. (a) Stackelberg game led by the supplier; (b) Stackelberg game led by the retailer; (c) Nash Equilibrium game between the supplier and the retailer.

the supplier increases her altruistic preference intensity but will decrease when the retailer increases his own altruistic preference intensity.

The preceding figures make it clear that when the situation is advantageous to the supplier, both the supplier and the retailer should raise their altruistic preferred service investment levels and control their altruistic preference intensities within a certain level with the intention of increasing their profits.

6.2. Members' Strategies and Profits under the Retailer's Advantage State. In common with the preceding discussion, we set $A=100, \omega_{t}=20$, and $\lambda=0.1$ and $\alpha=0.7$ and $\theta=0.7$ (to match the situation where products are more easily to sell through the distribution channel and have high homogeneity between two channels). Set $k_{s}$ increasing from $0 \sim 1, V_{t}$ increasing from $40 \sim 100$, and $V_{e}=40,70,100$ when discussing the effect of the supplier's preference intensities and the preferred service investment levels of both the supplier and retailer. This enables us to obtain the supplier's and retailer's profit changes, which are shown in Figure 12.

The preceding figure shows three surface in each $3 \mathrm{D}$ graph, which, respectively, represent the retailer's (a) and supplier's (b) profits affected by different preferred service investment levels of both the supplier and retailer and different preference intensities of the supplier under the retailer's advantaged state.

In moving from bottom to top of Figure 12(a), the observer sees that the surfaces, respectively, show the profits of the retailer, on the conditions that the retailer is selfinterested $\left(k_{r}=0\right)$ and the service investment levels of the supplier are, respectively, 40, 70 and 100 (be painted red, yellow and blue, respectively), with the continuous distribution of the service investment levels $\left(V_{t}\right.$ increases from $40 \sim 100)$ of the retailer and the preference intensities $\left(k_{s}\right.$ increases from $0 \sim 1$ ) of the supplier. Similarly, a reading from bottom to top of Figure 12(b) shows the supplier's different profits under the same condition as Figure 12(a).

Figure 12(a) shows that the retailer's profit will increase when the supplier raises her altruistic preferred service 


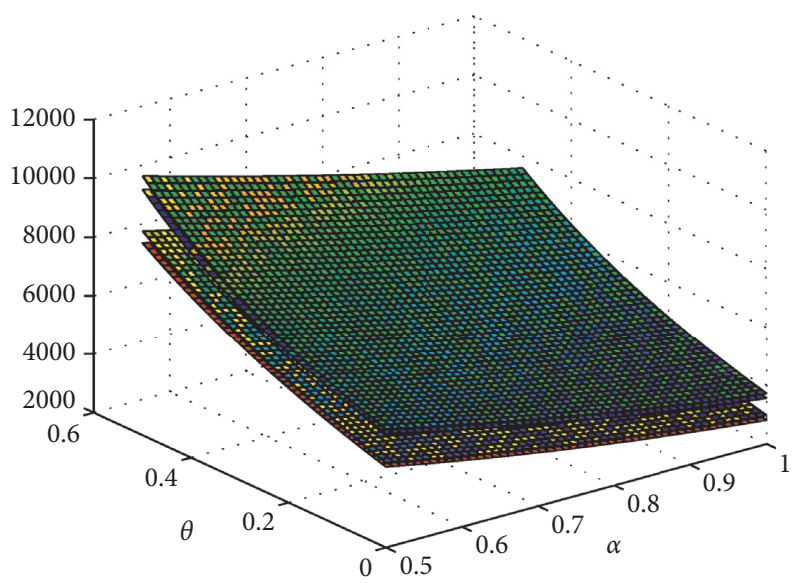

(a)

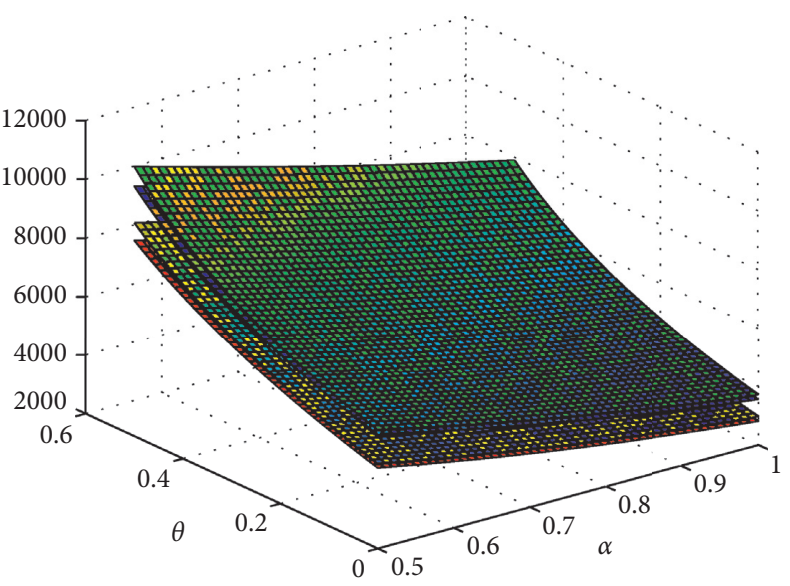

(b)

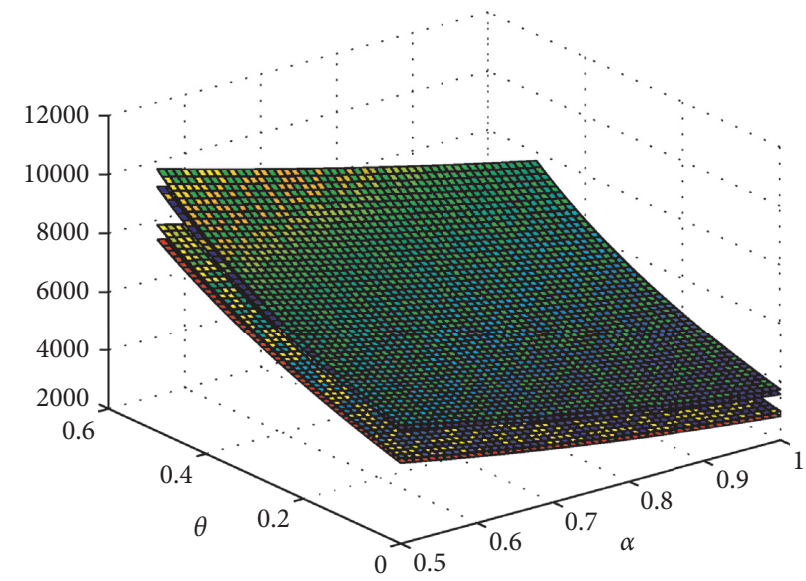

(c)

FIGURE 6: Comparisons of the supplier's profit in different preferred service investment combination modes based on different leaderfollower relationship modes when products are easier to sell in the distribution channel and have high heterogeneity between two channels $(0.5<\alpha<1,0<\theta<0.5)$. (a) Stackelberg game led by the supplier; (b) Stackelberg game led by the retailer; (c) Nash Equilibrium game between the supplier and retailer.

investment level or increases her altruistic preference intensity. Figure 12(b) shows that the supplier's profits will increase when she raises her altruistic preferred service investment level. The influence of the supplier's altruistic preference intensity on her own profit shows a track of initially increasing and then decreasing, which means that when the supplier keeps her altruistic preference at a moderate intensity, and she can obtain an optimal profit.

From Figure 12, we can see that when the situation is advantageous to the retailer, both the supplier and the retailer should raise their preferred service investment levels in order to increase their profits. However, the retailer's willingness of implementing service investment should be selfinterest and the supplier's should be altruistic. In addition, the supplier's preference intensity should be controlled within a certain level to ensure her own optimal profit.

We can see that the supplier's profit will increase when either the supplier or the retailer raise their service investment levels. Increases in the retailer's altruistic preference intensity can also increase the supplier's profit. The influence of the supplier's altruistic preference intensity on her own profit shows a trend of initially increasing and then decreasing, and this means when the supplier keeps her altruistic preference at a moderate intensity, she can obtain an optimal profit.

6.3. Some Enlightenment. Comparative analyses of the supplier's and retailer's profits in their respective advantaged states provide us with insight into coopetition strategies and supplier-retailer relationship-building methods in a dualchannel supply chain.

First, when products are easier to sell through the direct channel, the best cooperation mode for the supplier and retailer is one in which the later acts as the leader of the supply chain and they both implement altruistic preferred service investment. Both of them should raise their preferred service investment levels and should keep their altruistic intentions within a certain range.

Second, when products are easier to sell through the distribution channel, the best cooperation mode for the supplier and retailer is one in which the latter acts as the 


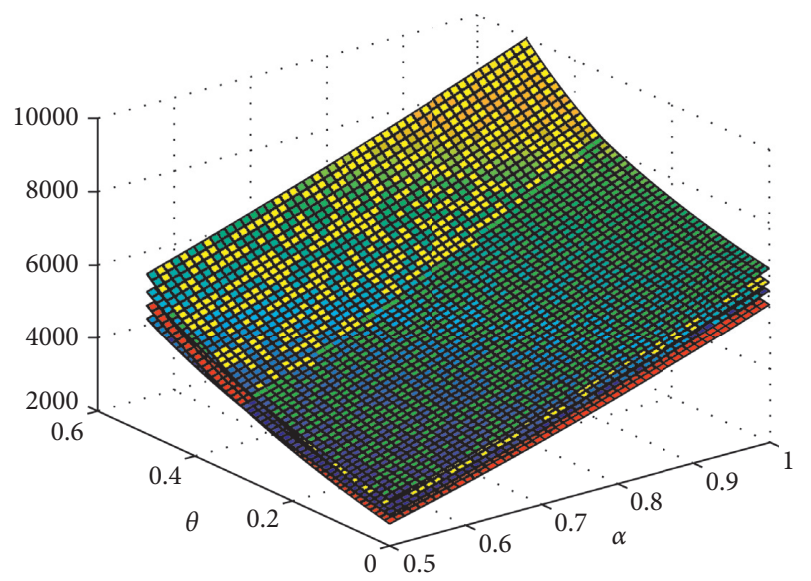

(a)

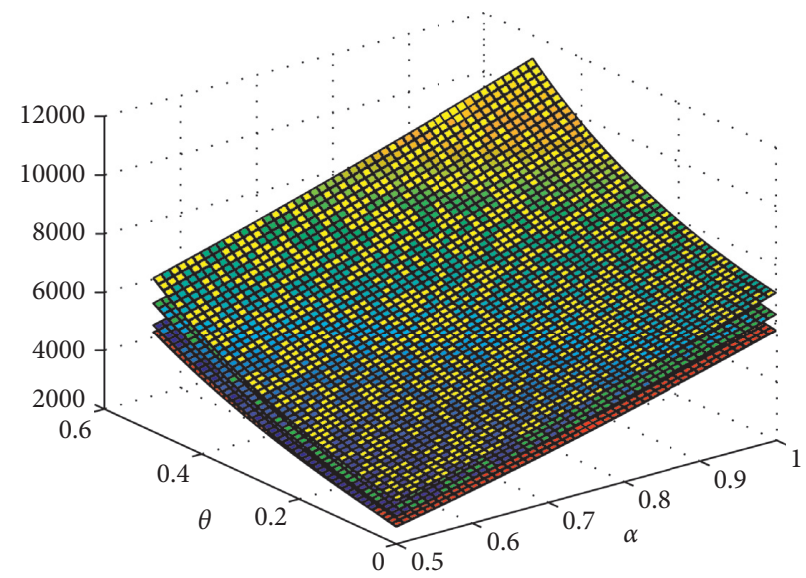

(b)

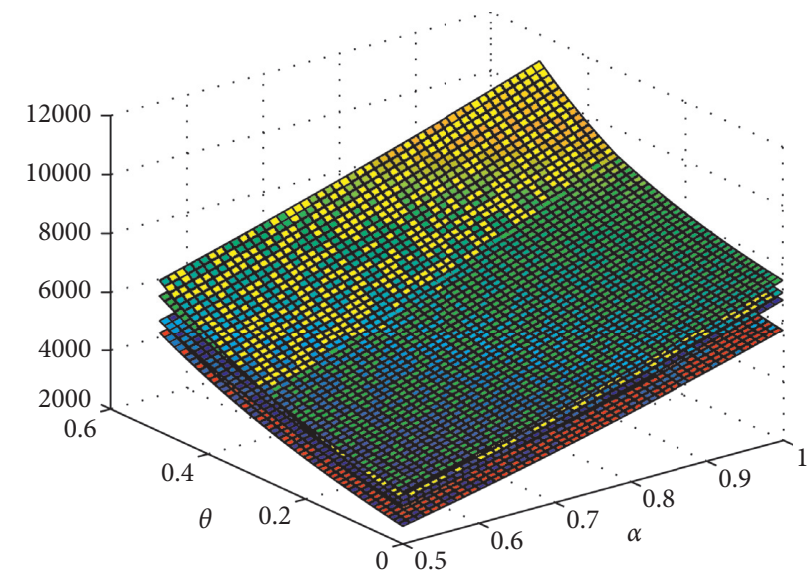

(c)

FIGURE 7: Comparisons of the retailer's profit in different preferred service investment combination modes based on different leaderfollower relationship modes when products are easier to sell in the distribution channel and have high heterogeneity between two channels $(0.5<\alpha<1,0<\theta<0.5)$. (a) Stackelberg game led by the supplier; (b) Stackelberg game led by the retailer; (c) Nash Equilibrium game between the supplier and retailer.

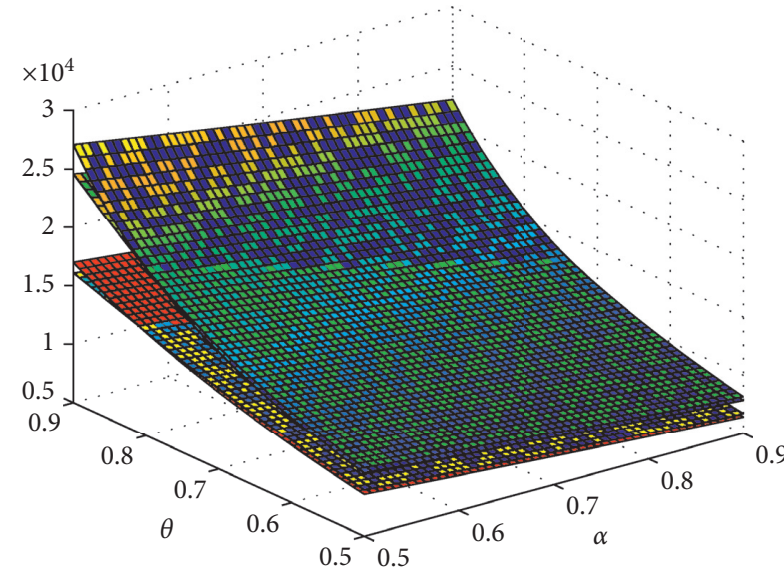

(a)

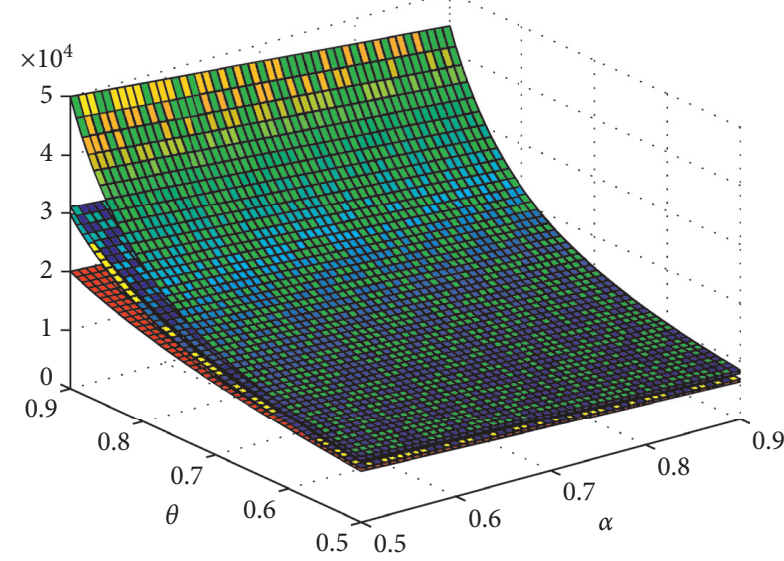

(b)

FIGURE 8: Continued. 


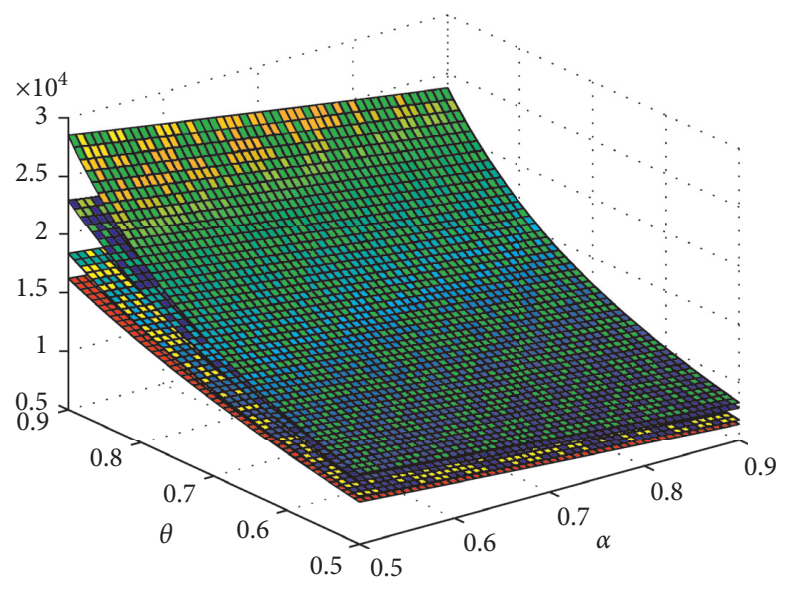

(c)

FIGURE 8: Comparisons of the supplier's profit in different preferred service investment combination modes based on different leaderfollower relationship modes when products are easier to sell in the distribution channel and have high homogeneity between two channels $(0.5<\alpha<1,0.5<\theta<1)$. (a) Stackelberg game led by the supplier; (b) Stackelberg game led by the retailer; (c) Nash Equilibrium game between the supplier and retailer.

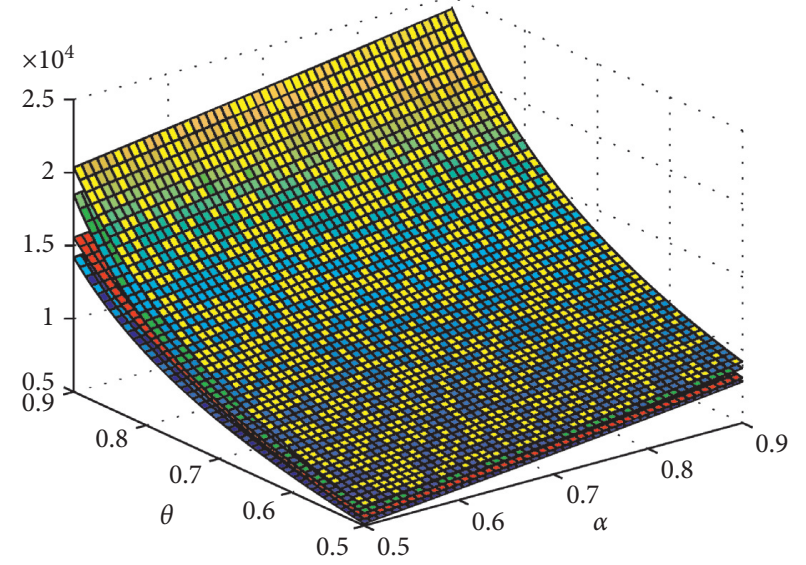

(a)

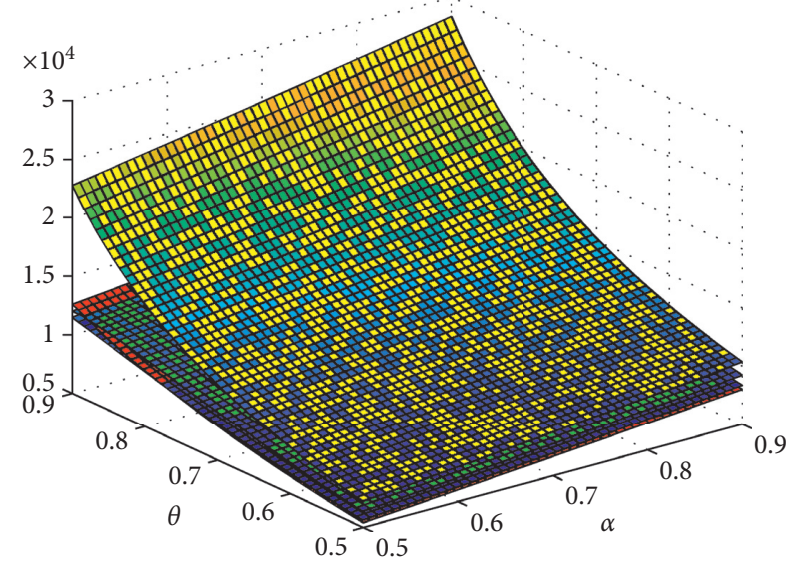

(b)

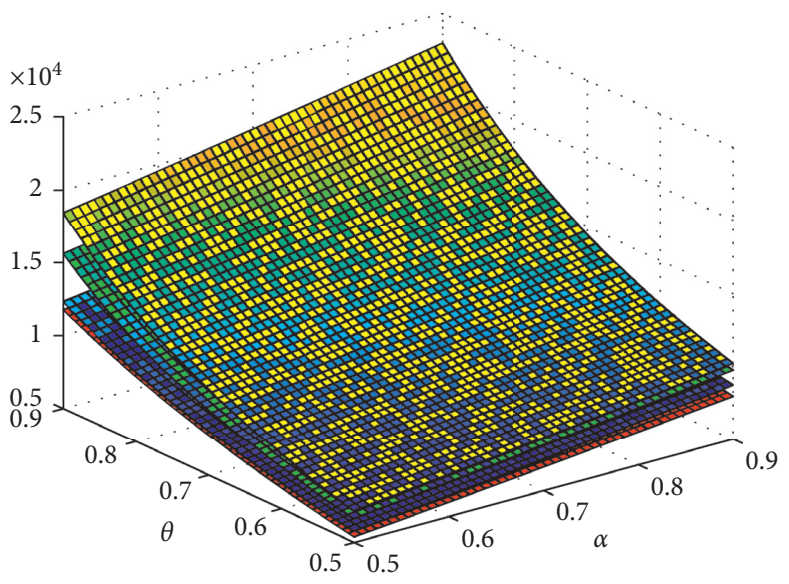

(c)

Figure 9: Comparisons of the retailer's profit in different preferred service investment combination modes based on different leaderfollower relationship modes when products are easier to sell in the distribution channel and have high homogeneity between two channels $(0.5<\alpha<1,0.5<\theta<1)$. (a) Stackelberg game led by the supplier; (b) Stackelberg game led by the retailer; (c) Nash Equilibrium game between the supplier and retailer. 


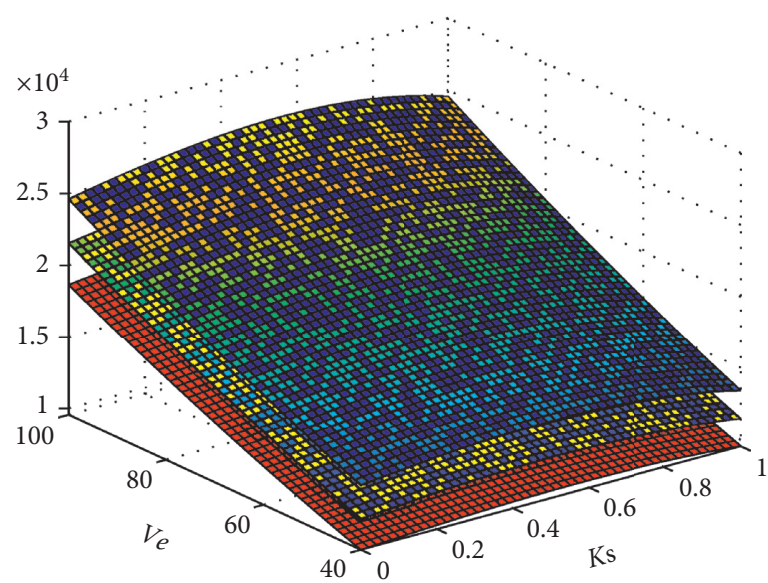

(a)

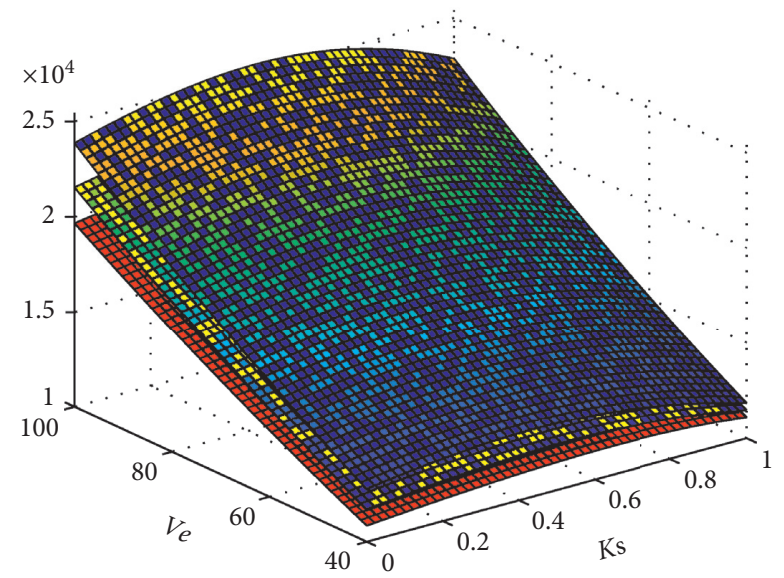

(b)

Figure 10: Comparisons of the supplier's profits under the supplier's advantaged state. (a) Supplier's profits are affected by the supplier's preference intensity and by both members' preferred service investment levels $\left(k_{r}=0.5, V_{t}=40,70,100\right)$; (b) supplier's profits are affected by the supplier's preferred service investment level and by both members' preference intensities $\left(V_{t}=70, k_{r}=0.1,0.5,0.9\right)$.

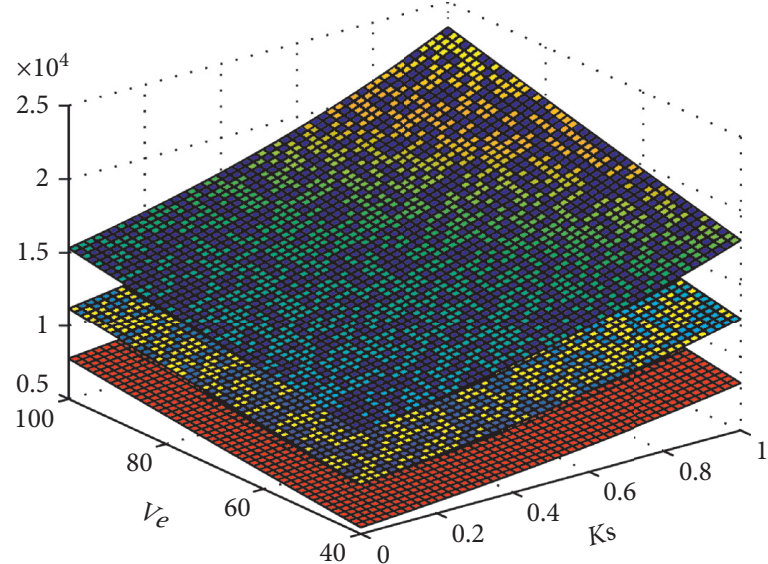

(a)

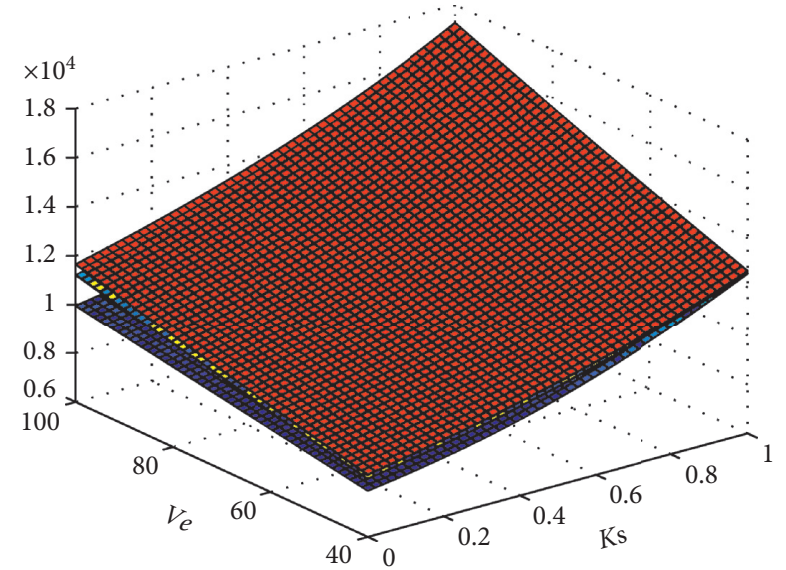

(b)

FIGURE 11: Comparisons of the retailer's profits in the supplier's advantaged state. (a) The retailer's profits are affected by the supplier's preference intensity and by both members' preferred service investment levels $\left(k_{r}=0.5, V_{t}=40,70,100\right)$; (b) the retailer's profits are affected by the supplier's preferred service investment level and by both members' preference intensities $\left(V_{t}=70, k_{r}=0.1,0.5,0.9\right)$.

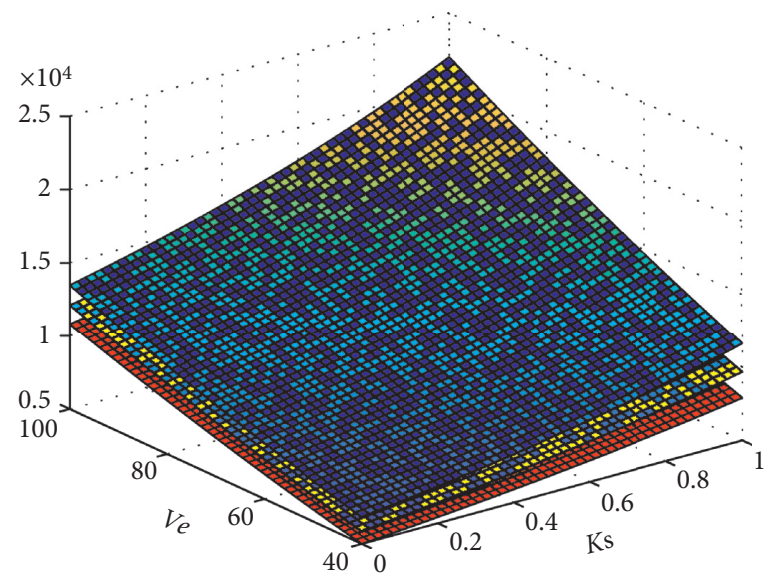

(a)

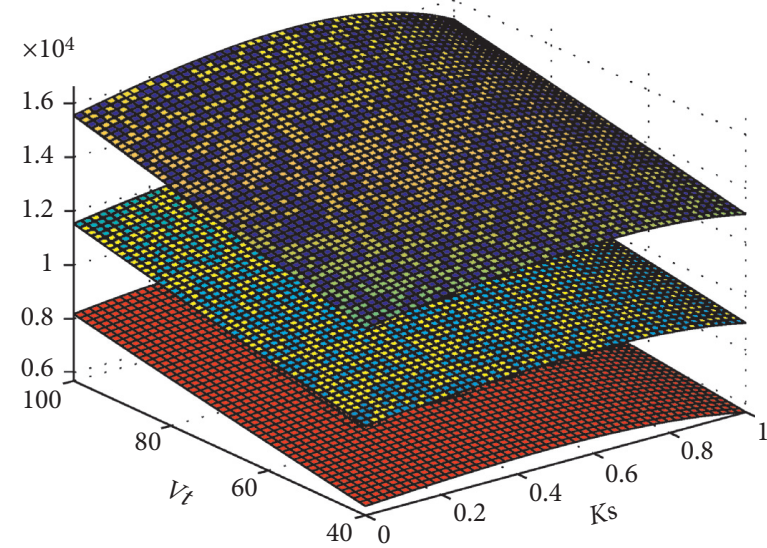

(b)

FIGURE 12: Comparisons of members' profits under the retailer's advantaged state. (a) Retailer's profits affected by the supplier's preference intensity and by both members' preferred service investment levels $\left(k_{r}=0, V_{e}=40,70,100\right)$; (b) supplier's profits affected by her preference intensity and by both members' preferred service investment levels $\left(k_{r}=0, V_{e}=40,70,100\right)$. 
leader of the supply chain, and the former implements altruistic preferred service investment and the retailer maintains the characteristic of self-interest. Both of them should raise their preferred service investment levels with the aim of achieving more profit; however, the retailer only cares about his own interest while the supplier is altruistic within a limited range.

Closer engagement with reality makes it possible to associate large retail enterprises and small-medium-sized suppliers with the real operation of the dual-channel supply chain. Suppose that there is a large and strong retail enterprise that has a physical advantage and is good at selling products that are suited to the traditional offline channel, such as clothing, cosmetics, and food. The retail enterprise usually acts as the leader in the dual-channel supply chain (like Wal-Mart) and selects an upstream supplier that has altruistic preference. While his powerful strength and advantage orientates him to be a self-interested member, it would like to implement more service investment for his own benefit. Meanwhile, the smallmedium-sized supplier, as a member that is relatively weaker, should implement appropriate altruistic service investment in the online channel. Her main concern is not just to build a solid relationship with the stronger retailer in the offline channel but also to ensure her own profit in the online channel.

When products are better suited to being sold through the online channel the dual-channel supply chain, such as electronics, audio-video products, or books, the advantage of the large retail enterprise will greatly decrease. This means he will need to mutually implement altruistic services investment with the upstream supplier, despite the fact that he is still the leader of the supply chain. Both the supplier and retailer should show altruism to each other in order to obtain more profits, but the intensities of altruistic preferences should be controlled within an appropriate range.

\section{Conclusions and Future Research}

This paper discusses the decision-making and profits of the supplier and retailer when both of them implement preferred service investment in a dual-channel supply chain under conditions of different product characteristics, different preferred service investment combination modes, and different leader-follower relationship modes between them. On this basis, we obtained the supplier's and retailer's advantaged states and the grounds on which they participated in the operation of the dual-channel supply chain. We explored how the preferred service investment levels and the preferred intensities of the supplier and retailer influenced their optimal decision-making and profits in their respective advantage states. In referring to the supplier and retailer, we provided insight into the cooperation strategies and relationship-building methods between them.

The innovation and contribution of this research is it integrates multiple factors to discuss which will affect the operation performance of the dual-channel supply chain, including the degrees of products selling difficulty between dual channels, the levels of service investment that the supplier and retailer implement for improving product sales, the subordinate relationship mode between the supplier and retailer, and the preference characteristics of their service investment. We discuss the influences of different factor combinations on the decision-making and profits of the supplier and retailer by classifying their leader-follower relationship modes and that can help us to obtain more comprehensive investigations and comparisons for our study on the optimal strategy selection of the supplier and retailer in the dual-channel supply chain.

We also acknowledge that this paper has a number of shortcomings.

First, for convenience of analysis, we use linear functions to express the influence that the price and service investment have on the sales volume in the dual-channel supply chain. However, we realize that these expressions may not be completely consistent with the actual relationship between the product sales and the influencing factors in current market operation, and we should therefore choose more practical nonlinear functions with the intention of more completely expressing these relationships and thereby improving the authenticity of reflections on dual-channel supply chain operation in our future research.

Second, in order to highlight key points, we do not take the cost of service investment into account when analyzing the influence of member's service investment level. However, we know that, during the process of implementing service investment, members' cost will inevitably exist and will certainly change in accordance with the level of service investment, which will therefore also affect members' decision-making and profits. It is necessary to conduct more in-depth and practical discussions that engage with the cost of service investment.

Third, this paper only refers to members' self-interest and altruistic preferences when discussing the characteristics of members' behavior preferences. However, we know that members in the supply chain, who are decision-makers with bounded rationality, often show various preference characteristics when participating in the supply chain operation; furthermore, the type and degree of these preferences will vary in terms of their effects on members' decision-making and profits. That means it is more meaningful for us to examine the influence that multiple preference characteristics have on members because this will enable us to more accurately reflect on the intentions and effects of their decisions. We should therefore consider incorporating multiple behaviors and preference characteristics in future research.

\section{Data Availability}

The data used to support the findings of this study are included within the article and the supplementary information file.

\section{Conflicts of Interest}

The authors declare that they have no conflicts of interest. 


\section{Acknowledgments}

This work was supported by the project of National Natural Science Foundation of China (NSFC) (Project no. 71840003) and Science and Technology Development Fund of University of Shanghai for Science and Technology (USST), Shanghai (no. 2018KJFZ043).

\section{Supplementary Materials}

In this article, Figures $2-12$ are drawn by using MATLAB programming language. We now provide the MATLAB code corresponding to those Figures in the supplementary materials. (Supplementary Materials)

\section{References}

[1] A. A. Tsay and N. Agrawal, "Channel conflict and coordination in the E-commerce age," Production and Operations Management, vol. 13, no. 1, pp. 93-110, 2004.

[2] Q. Lu and N. Liu, "Effects of e-commerce channel entry in a two-echelon supply chain: a comparative analysis of singleand dual-channel distribution systems," International Journal of Production Economics, vol. 165, no. 1, pp. 100-111, 2015.

[3] R. Yan and Z. Pei, "Retail services and firm profit in a dualchannel market," Journal of Retailing and Consumer Services, vol. 16, no. 4, pp. 306-314, 2009.

[4] A. A. Tsay and N. Agrawal, "Channel dynamics under price and service competition," Manufacturing \& Service Operations Management, vol. 2, no. 4, pp. 372-391, 2000.

[5] S. Strauss, The Impact of Free Riding on Price and Service Competition in the Presence of E-Commerce Retailers, Yale School of Management Working Papers, New Haven, CT, USA, 2002.

[6] A. J. Rohm and V. Swaminathan, "A typology of online shoppers based on shopping motivations," Journal of Business Research, vol. 57, no. 7, pp. 748-757, 2004.

[7] A. Dumrongsiri, M. Fan, A. Jain, and K. Moinzadeh, "A supply chain model with direct and retail channels," European Journal of Operational Research, vol. 187, no. 3, pp. 691-718, 2008.

[8] B. Dan, G. Xu, and C. Liu, "Pricing policies in a dual-channel supply chain with retail services," International Journal of Production Economics, vol. 139, no. 1, pp. 312-320, 2012.

[9] L. Wang, H. Song, and Y. Wang, "Pricing and service decisions of complementary products in a dual-channel supply chain," Computers \& Industrial Engineering, vol. 105, pp. 223-233, 2017.

[10] G. Li, L. Li, and J. Sun, "Pricing and service effort strategy in a dual-channel supply chain with showrooming effect," Transportation Research Part E: Logistics and Transportation Review, vol. 126, pp. 32-48, 2019a.

[11] D. Wu, J. Chen, P. Li, and R. Zhang, "Contract coordination of dual channel reverse supply chain considering service level," Journal of Cleaner Production, vol. 260, no. 1, p. 121071, 2020.

[12] D. W. Carlton and J. A. Chevalier, "Free riding and sales strategies for the internet," The Journal of Industrial Economics, vol. 49, no. 4, pp. 441-461, 2001.

[13] F. Bernstein, J.-S. Song, and X. Zheng, "Free riding in a multichannel supply chain," Naval Research Logistics, vol. 56, no. 8, pp. 745-765, 2009.

[14] B. Dan, C. Liu, G. Xu, and X. Zhang, "Pareto improvement strategy for service-based free-riding in a dual-channel supply chain," Asia-Pacific Journal of Operational Research, vol. 31, no. 6, Article ID 1450050, 2014.

[15] R. Yan and Z. Pei, "Information asymmetry, pricing strategy and firm's performance in the retailer- multi-channel manufacturer supply chain," Journal of Business Research, vol. 64, no. 4, pp. 377-384, 2011.

[16] J. Chen and Y. Yang, "Service cooperation policy in a dualchannel supply chain under service differentiation," American Journal of Industrial and Business Management, vol. 4, no. 6, pp. 284-294, 2014.

[17] Q. X. Li, X. L. Chen, Y. M. Huang et al., "The impacts of green innovation input and channel service in a dual-channel value chain," International Journal of Environmental Research and Public Health, vol. 16, no. 22, pp. 1-26, 2019 b.

[18] H. A. Simon, Administrative Behavior: A Study of DecisionMaking Processes in Administrative Organization, Simon \& Schuster Inc., New York, NY, USA, 4th edition, 1997.

[19] X. H. Gan, S. Sethi, and H. M. Yan, "channel coordination with a risk-neutral supplier and a downside risk -averse retailer," Production and Operations Management, vol. 14, no. 1, pp. 80-89, 2005.

[20] C. X. Wang and S. Webster, "Channel coordination for a supply chain with a risk-neutral manufacturer and a lossaverse retailer," Decision Sciences, vol. 38, no. 3, pp. 361-389, 2007.

[21] B. Li, P.-W. Hou, P. Chen, and Q.-H. Li, "Pricing strategy and coordination in a dual channel supply chain with a risk-averse retailer," International Journal of Production Economics, vol. 178, pp. 154-168, 2016.

[22] H. T. Cui, J. S. Raju, and Z. J. Zhang, "Fairness and channel coordination," Management Science, vol. 53, no. 8, pp. 1303-1314, 2007.

[23] C. D. Ozgun, F. Y. Chen, and J. Li, "Channel coordination under fairness concerns and nonlinear demand," European Journal of Operational Research, vol. 207, no. 3, pp. 1321-1326, 2010.

[24] L. Wang and K. H. Cheng, "Effect of fairness preference on dual-channel supply chain," in Proceedings of the International Conference on Management Science \& Engineering, July 2013.

[25] Y. Ren, D. C. Croson, and R. T. A. Croson, “The overconfident newsvendor," Journal of the Operational Research Society, vol. 68, no. 5, pp. 496-506, 2017.

[26] Y. L. Wu and J. S. Hu, "Supply chain network dual-channel equilibrium model with overconfident retailers," Operations Research and Management Science, vol. 27, no. 1, pp. 96-102, 2018, in Chinese.

[27] S. M. Disney and T. Hosoda, "The benefit of altruistic behavior achieved by the out policy with unmatched proportional feedback gains in a two-echelon supply chain," in Proceedings of the International Conference on Production Research, Valparaiso, Chile, August 2013.

[28] K. R. Shi and H. J. Ma, "Evolution of trust in a dual-channel supply chain considering reciprocal altruistic behavior," Advances in Complex Systems, vol. 19, no. 6, pp. 330-337, 2017.

[29] M. Nagarajan and G. Sošić, "Game-theoretic analysis of cooperation among supply chain agents: review and extensions," European Journal of Operational Research, vol. 187, no. 3, pp. 719-745, 2008.

[30] G. Aust and U. Buscher, "Vertical cooperative advertising and pricing decisions in a manufacturer-retailer supply chain: a game-theoretic approach," European Journal of Operational Research, vol. 223, no. 2, pp. 473-482, 2012. 
[31] G. Cai, Z. G. Zhang, and M. Zhang, "Game theoretical perspectives on dual-channel supply chain competition with price discounts and pricing schemes," International Journal of Production Economics, vol. 117, no. 1, pp. 80-96, 2009.

[32] B. C. Giri and B. Roy, "Dual-channel competition: the impact of pricing strategies, sales effort and market share," International Journal of Management Science and Engineering Management, vol. 11, no. 4, pp. 203-212, 2015.

[33] T.-M. Choi, S. W. Wallace, and Y. Wang, "Risk management and coordination in service supply chains: information, logistics and outsourcing," Journal of the Operational Research Society, vol. 67, no. 2, pp. 159-164, 2016.

[34] W. Li, J. Chen, G. Liang, and B. Chen, "Money-back guarantee and personalized pricing in a Stackelberg manufacturer's dual-channel supply chain," International Journal of Production Economics, vol. 197, pp. 84-98, 2018.

[35] T. Xiao and D. Yang, "Price and service competition of supply chains with risk-averse retailers under demand uncertainty," International Journal of Production Economics, vol. 114, no. 1, pp. 187-200, 2008.

[36] F. Zhang and C. Wang, "Dynamic pricing strategy and coordination in a dual-channel supply chain considering service value," Applied Mathematical Modelling, vol. 54, pp. 722-742, 2018.

[37] L. Ren, Y. He, and H. Song, "Price and service competition of dual-channel supply chain with consumer returns," Discrete Dynamics in Nature and Society, vol. 2014, Article ID 565603, 10 pages, 2014. 